\title{
Avaliação de um Modelo de Maturidade para Governança Ágil em Tecnologia da Informação e Comunicação
}

\author{
Humberto Rocha de Almeida Neto ${ }^{1,2}$, Edviges Mariza Campos de Magalhães ${ }^{3}$, \\ Hermano Perrelli de Moura ${ }^{1}$, José Gilson de Almeida Teixeira Filho ${ }^{1,6}$, Claudia \\ Cappelli $^{4}$, Luiz Maurício Fraga Martins ${ }^{5}$ \\ ${ }^{1}$ Centro de Informática - Universidade Federal de Pernambuco (UFPE) \\ CEP 50740-540 - Recife - PE - Brazil \\ ${ }^{2}$ Serviço Federal de Processamento de Dados (SERPRO) \\ CEP 520609-010 - Recife - PE - Brazil \\ ${ }^{3}$ Empresa de Tecnologia e Informações da Previdência Social (DATAPREV) \\ CEP 58040-000 - João Pessoa - PB - Brazil
}

${ }^{4}$ Departamento de Informática Aplicada - Universidade Federal do Estado do Rio de Janeiro (UNIRIO)

CEP 22290-240 - Rio de Janeiro - RJ - Brazil

${ }^{5}$ Departamento de Engenharia de Informática - Universidade de Coimbra (CISUC) Pólo II. 3030-290 - Coimbra - Portugal
${ }^{6}$ Departamento de Administração - Universidade Federal de Pernambuco (UFPE) CEP 50740-540 - Recife - PE - Brazil
\{hran, hermano, jgatf\} @cin.ufpe.br, edviges.magalhaes@dataprev.gov.br, claudia.cappelli@uniriotec.br, lmartedei.uc.pt

Abstract. Agile Governance in Information and Communication Technology (ICT) is an area of research and practice on the rise, that which has been placed as an innovative proposal based on the principles and values of the Manifesto for Agile Software Development. However, the adoption of practices in this area is still can be considered a challenging task, mainly due to relative insipience of the area. Given this context, it is important to define initiatives that support the adoption of a good Agile Governance in ICT in organizations. These initiatives can quote the MAnGve Maturity Model (M3): A maturity model for Agile Governance in ICT. This article presents the results of two evaluations carried out with alpha and beta versions of M3: a maturity model for Agile Governance in ICT. The evaluations were conducted through a survey with experts and focus group culminating in inputs that supported the evolution of the proposed maturity model for its version 1.0.

Resumo. A Governança Ágil em Tecnologia da Informação e Comunicação (TIC) é uma área de pesquisa e prática em ascensão, a qual vem sendo colocada como uma proposta inovadora baseada nos princípios e valores do Manifesto para Desenvolvimento Ágil de Software. No entanto, a adoção de práticas para este domínio ainda pode ser considerada uma tarefa desafiadora, devido, principalmente, à relativa incipiência da área. . Diante 
deste contexto, torna-se importante a definição de iniciativas que apoiem a adoção de uma boa Governança Ágil em TIC nas organizações. Entre estas iniciativas é possível citar o MAnGve Maturity Model (M3): Um modelo de maturidade para Governança Ágil em TIC. Este artigo apresenta os resultados de duas avaliações realizadas com as versões alfa e beta do M3. As avaliações foram realizadas por meio de um survey com especialistas e um grupo focal culminando em insumos que embasaram a evolução do modelo de maturidade proposto para sua versão 1.0.

\section{Introdução}

A aplicação adequada e eficiente de recursos de Tecnologia da Informação e Comunicação (TIC) tem exercido papel fundamental na garantia de retorno nos investimentos das organizações. Ao longo dos últimos anos, a TIC tornou-se um dos principais ativos a serem governados.

De acordo com BLOOM (1991), a palavra Governança deriva do verbo grego $\kappa v \beta \varepsilon \rho v \alpha ́ \omega$ [kubernáo], o qual significa dirigir (guiar, governar). Esta palavra foi utilizada pela primeira vez em um sentido metafórico por Platão (380 A.C.) em sua obra "A República". O termo Governança começou a se difundir por meio do Fundo Monetário Internacional e do Banco Mundial, a partir da Conferência de Bretton Woods (US DEPARTMENT OF STATE, 1944).

A partir destas definições, torna-se relevante diferenciar Governança Corporativa e Governança em TIC. A Governança Corporativa é descrita por CADBURY (1992) como o conjunto de processos, costumes, políticas, leis e instituições que afetam a maneira como uma organização é dirigida, administrada ou controlada. Esta Governança inclui as relações entre as várias partes envolvidas e os fins para os quais a sociedade é governada. Por outro lado, a Governança em TIC é definida pelo IT Governance Institute como um subconjunto da Governança Corporativa, sendo considerada uma disciplina focada em TIC e seus sistemas de desempenho e gestão de riscos (ITGI, 2001).

Diversas iniciativas têm sido propostas com objetivo de promover uma Governança em TIC mais eficiente (GREMBERGEN; DEHAES, 2008; ISACA, 2012; WEIL; ROSS, 2005). No contexto deste trabalho, iniciativas para apoio à Governança em TIC são tidas como práticas, modelos, guias, frameworks e demais iniciativas que contribuem direta ou indiretamente para uma boa Governança. A partir desta perspectiva, entende-se, por exemplo, que a ITIL - Information Technology Infrastructure Library (ITIL, 2009) pode contribuir por meio de sua biblioteca de boas práticas em gerenciamento de serviços de TIC. Por sua vez, o COBIT - Control Objectives for Information and related Technology (ISACA, 2012) contribui com seu framework para alinhamento entre TIC/negócio e assim por diante.

Apesar de essas iniciativas serem em geral muito bem estruturadas, o formalismo por muitas vezes excessivo na descrição de seus processos, somado à grande quantidade de informações disponibilizadas, torna-as consideravelmente complexas para uma adoção em um contexto mais ágil e prático (ISACA, 2013).

Alguns autores afirmam que as práticas, modelos, guias e frameworks de Governança propostos são em sua grande maioria burocráticos, consomem muito tempo

ALMEIDA NETO, H. R.; MAGALHÃES, E. M. C.; MOURA, H. P.; et al.

Avaliação de um Modelo de Maturidade para Governança Ágil em Tecnologia da Informação e Comunicação

iSys - Revista Brasileira de Sistemas de Informação, Rio de Janeiro, vol. 8, No. 4, pp. 44-79, 2015 
e não apresentam detalhes de orientação sobre como efetivamente implementar e implantar os instrumentos de gestão e mecanismos de Governança (BARTENSCHLAGER; GOEKEN, 2010; HESTON; PHIFER, 2011; KTATA; LÉVESQUE, 2009). Sendo assim, é possível observar certo conflito entre um formalismo por algumas vezes excessivo e a agilidade imposta por um mercado cada vez mais competitivo.

Por muitas vezes a burocracia aplicada a estas iniciativas tenta ser justificada como algo essencial à sua organização. No entanto, quando as organizações tentam adotá-las, especialmente as que não possuem tanto know how em Governança, acabam se deparando com dificuldades algumas práticas. Normalmente isto as leva a consultorias especializadas, gerando custos consideráveis, como tentativa em obter os reais benefícios de suas adoções.

Em meados de 2001, pode-se observar uma questão semelhante no cenário de desenvolvimento de software da época. Naquele período, metodologias como a Rational Unified Process (RUP) (IBM RATIONAL, 2011), tidas como precursoras ao desenvolvimento prescritivo de software, também se depararam com alguns problemas. Dificuldades para reação a mudanças constantes, colaboração com o cliente, geração de produtos de qualidade (respeitando prazo e qualidade), são apenas alguns dos problemas que podem ser citados. Este cenário motivou o surgimento do Manifesto for Agile Software Development (BECK et al., 2001), manifesto que se pautou em um conjunto de princípios e valores envolvendo perspectivas inovadoras para os métodos de desenvolvimento de software da época.

"A engenharia de software ágil combina filosofia com um conjunto de princípios de desenvolvimento. A filosofia defende a satisfação do cliente e a entrega de incremental prévio; equipes de projetos pequenas e altamente motivadas; métodos informais; artefatos de engenharia de software mínimos e, acima de tudo, simplicidade no desenvolvimento geral. Os princípios de desenvolvimento priorizam a entrega mais que a análise e projeto (embora essas atividades não sejam desencorajadas); também priorizam a comunicação ativa e contínua entre desenvolvedores e clientes" (PRESSMAN, 2011).

Com esta mesma perspectiva em mente, este trabalho acredita que a Governança em TIC contemporânea também carece de iniciativas mais ágeis e que estas iniciativas podem receber influências dos princípios e valores do Manifesto for Agile Software Development. LUNA et al. (2010) apresentam um estudo evidenciando a relação entre os fatores críticos de sucesso para Governança em TIC e o Manifesto for Agile Software Development. Por meio deste estudo é possível observar uma forte relação entre Governança em TIC e agilidade no desenvolvimento de software. Por exemplo, entre os resultados deste estudo, para o fator crítico de sucesso: "F7 - Foco em pequenas vitórias consecutivas e na disseminação dos resultados destas iniciativas", não foram identificadas relações apenas com dois dos princípios do Manifesto for Agile Software Development. Este entre outros resultados apresentados no trabalho reforçam a existência de relação entre ambas às áreas (Governança em TIC e agilidade no desenvolvimento de software). 
Além disto, a partir deste mesmo estudo, os autores apresentam um conceito inovador batizado de Governança Ágil em TIC. Para estes autores, Governança Ágil em TIC pode ser definida como:

"The process of defining and implementing the IT infrastructure that provides support to strategic business objectives of the organization, which is jointly owned by IT and the various business units and instructed to direct all involved in obtaining competitive differential strategic through the values and principles of the Agile Software Development Manifesto".

De acordo com recentes estudos (LUNA et al., 2014), a Governança Ágil é tida como um domínio em ascensão e que vem sendo sugerido como uma proposta inovadora baseada no uso de princípios e valores do Manifesto for Agile Software Development sobre o contexto da Governança em TIC convencional. No entanto, adotar uma boa Governança Ágil em TIC ainda é considerada uma tarefa desafiadora devido, principalmente, a multidisciplinaridade e relativa incipiência da área (LUNA et al., 2014). Se por um lado há um conjunto bem estabelecido de princípios, práticas e valores ágeis em áreas subjacentes a Governança Ágil em TIC (a exemplo de Desenvolvimento de Software), por outro lado, esse conjunto ainda requer evoluções em outras subáreas (a exemplo de Gerenciamento de Serviços, Operações, Infraestrutura, dentre outras).

Quando passamos a analisar a aplicação da agilidade sobre Governança, estas podem a princípio parecer bastante antagônicas (um oximoro ${ }^{1}$ ). A Governança denota a ideia de mecanismos, controle, responsabilidade e autoridade, enquanto agilidade transmite a ideia de certa informalidade, simplicidade, experimentação. No entanto, se o objetivo da organização é atingir a agilidade dos negócios, acredita-se que esta não pode ser alcançada sem o compromisso de todos, o qual, não pode ser atingido sem uma boa Governança.

Durante os avanços em nossas pesquisas, tornou-se possível constatar que as metodologias de desenvolvimento de software (sejam ágeis ou tradicionais) têm recebido apoio de iniciativas para apoio a evolução de maturidade seus processos e/ou práticas (SOFTEX, 2011; NAWROCKI; WALTER; WOJCIECHOWSKI, 2001; PATEL; RAMACHANDRAN, 2009; SEI, 2006a; YIN, 2011). Iniciativas semelhantes também tem apoiado a evolução de maturidade na Governança em TIC tradicional (ISACA, 2007; OGC, 2007). No entanto, para o contexto de Governança Ágil em TIC, foi possível perceber que estas mesmas iniciativas para evolução de maturidade ainda estão incipientes. Entre tais iniciativas destacam-se os modelos de maturidade.

Um modelo de maturidade é uma estrutura conceitual, composta por processos bem estabelecidos, por meio do qual uma organização desenvolve-se de modo sistêmico a fim de atingir um estado futuro desejado. A cada degrau alcançado nesta jornada, um modelo de maturidade reconhece e sinaliza o amadurecimento progressivo da organização (CRAWFORD, 2001; PMI, 2003; PRADO, 2008; SEI, 2006). FILHO PAULA; PÁDUA WILSON (2009) faz uma analogia onde um processo é descrito como uma receita a ser seguida.

\footnotetext{
${ }^{1}$ Figura de linguagem em que ocorre falso paradoxo, apesar das palavras terem sentido contrário à formulação faz sentido. (ISEB, 2009).

ALMEIDA NETO, H. R.; MAgAlHÃES, E. M. C.; MOURA, H. P.; et al.

Avaliação de um Modelo de Maturidade para Governança Ágil em Tecnologia da Informação e Comunicação iSys - Revista Brasileira de Sistemas de Informação, Rio de Janeiro, vol. 8, No. 4, pp. 44-79, 2015
} 
Neste sentido, CARMEL (2005) descreve que o entendimento coletivo de um fenômeno é incompleto se os estágios de maturidade não forem identificados e isto se torna ainda mais relevante quando o fenômeno está nos seus estágios iniciais de estudo. $\mathrm{O}$ autor afirma que quanto mais maduro o fenômeno observado, menor o fator de impacto da relevância destes modelos de maturidade.

Além disto, GRANT e PENNYPACKER (2006) afirmam que as organizações modernas de pequeno, médio ou grande porte devem utilizar os conceitos e modelos de maturidade para acelerar o crescimento no que diz respeito às práticas, processos, definição de responsabilidades e aumento do nível de maturidade. A partir do diagnóstico de um nível de maturidade de uma organização, torna-se possível prever seu futuro desempenho dentro de determinada área ou conjunto de disciplinas. Um nível de maturidade é uma etapa evolucionária definida na melhoria de processos onde cada nível estabiliza uma parte importante dos processos organizacionais.

A experiência demonstra que as organizações funcionam melhor quando concentram seus esforços de melhoria de processos em um número controlado de áreas, as quais exigem um esforço cada vez mais sofisticado à medida que a organização melhora (SEI, 1995). Neste sentido, os modelos de maturidade buscam uma unificação de uma mesma visão, tratando a evolução da maturidade como estágios evolutivos. Nestes estágios, as organizações vão evoluindo e conquistando um maior grau de maturidade a cada etapa (PRADO, 2008; SOLER, 2005).

Diante deste contexto, podemos afirmar que a natureza ainda em ascensão da Governança Ágil em TIC, somada à carência por mecanismos para evolução de maturidade neste campo de pesquisa, reforça o caráter inovador e relevante da proposta deste trabalho: O desenvolvimento de um modelo de maturidade para Governança Ágil em TIC.

Este artigo apresenta os resultados de duas avaliações realizadas com as versões alfa e beta do MAnGve Maturity Model (M3): um modelo de maturidade para Governança Ágil em TIC. As avaliações foram realizadas por meio de um survey com especialistas e um grupo focal culminando em insumos que embasaram a evolução do modelo proposto para sua versão 1.0. As seções seguintes são estruturadas da seguinte maneira: a Seção 2 apresenta a metodologia utilizada durante este trabalho de pesquisa, a Seção 3 apresenta uma visão geral do modelo proposto e a Seção 4 apresenta os resultados obtidos durante as avaliações. Por fim, a Seção 5 apresenta as devidas conclusões e trabalhos futuros para esta pesquisa.

\section{Trabalhos Relacionados e Contribuições}

Alguns trabalhos relacionados e contribuições foram identificados ao longo desta pesquisa. KORHONEN; YILDIZ; MYKKÄNEN (2009) apresentam uma das primeiras tentativas em criar um modelo de referência para a Governança de Segurança em SOA. LI; BIENNIER; GHEDIRA (2011) propõem um método de Governança Ágil para arquiteturas industriais multi-camadas, buscando atender aos princípios de Serviços de TIC (utilizando SOA e BPMN) combinados com as teorias Lean e Six Sigma. Para tal, foram definidos três níveis para o método: Negócios, serviços e aplicação.

Por outro lado, WILKINSON (2006) descreve uma estratégia para empresa adaptativa na HP. Neste trabalho são apresentados estágios de maturidade que tratam da 
típica evolução de uma empresa até seu estágio adaptativo. DOVE; HARTMAN; BENSON (1996) apresentam um modelo de maturidade para avaliar a competência de organizações em se adaptar diante de mudanças.

SUN; ZHANG; VALOTA (2005), por sua vez, propõem um conjunto de ferramentas que analisam e medem quantitativamente a agilidade de organizações de manufatura. YUSUF et al. (2004) utiliza um modelo conceitual que consiste em quatro dimensões para avaliar a maturidade de uma agile supply chain. Por fim, AMBLER (2009) define um modelo de maturidade para Governança de processos ágeis de desenvolvimento de software. Este mesmo autor afirma que a Governança não é algo que é comumente associada a projetos de desenvolvimento ágil de software, mas que, no entanto, os projetos ágeis, assim como todos os outros projetos, podem e devem ser governados.

Desta forma, baseado nas subáreas identificadas para Governança Ágil em nossa revisão sistemática de literatura (LUNA et al., 2014), podemos observar que os trabalhos apresentados abordam temas diversos: Os dois primeiros abordam SOA Governance (KORHONEN; YILDIZ; MYKKÄNEN, 2009; LI; BIENNIER; GHEDIRA, 2011); os dois seguintes Enterprise Architecture (DOVE; HARTMAN; BENSON, 1996; WILKINSON, 2006); e os restantes Agile Manufacturing (YUSUF et al., 2004) e Governance for Agile Software Development (AMBLER, 2009) respectivamente.

Apenas três destes trabalhos descrevem uma clara proposta para evolução de maturidade baseada em estágios, baseando-se em uma postura mais sistemática e gradual a mudanças. Neste sentido, é possível observar trabalhos atuando em: Governance for Enterprise Architecture, Agile Manufacturing e Agile Software Development, mas não em Agile IT Governance.

Além disto, os trabalhos que envolvem TIC de alguma maneira, o fazem apenas sob um determinado aspecto: Segurança da Informação, Desenvolvimento de Software ou Serviços de TIC. Nenhum destes trabalhos apresenta uma proposta de Governança Ágil em TIC de maneira holística, ou seja, tratando a TIC como um todo.

Levando em consideração estas lacunas, o M3 traz contribuições para a subárea de Agile IT Governance, apresentando um modelo que apoia a evolução sistemática e gradual de maturidade em Governança Ágil em TIC, baseado em estágios de maturidade e seguindo uma abordagem holística para TIC.

\section{Metodologia da Pesquisa}

MARCONI e LAKATOS (2009) afirmam que a definição instrumental metodológica deve estar diretamente relacionada ao problema a ser estudado. Desta forma, uma pesquisa deve ser rigorosamente analisada antes mesmo de sua execução propriamente dita. Visando atender ao objetivo central deste trabalho, foram definidos alguns procedimentos e técnicas. O Quadro 1 resume as abordagens metodológicas utilizadas para desenvolvimento deste trabalho.

Quadro 1 - Resumo das Abordagens Metodológicas

\begin{tabular}{|l|l|}
\hline Classificação da Pesquisa quanto: \\
\hline Ao Objetivo & Exploratória. \\
\hline Aos Procedimentos Técnicos & Pesquisa Bibliográfica; \\
\hline
\end{tabular}

ALMEIDA NETO, H. R.; MAgALHÃES, E. M. C.; MOURA, H. P.; et al.

Avaliação de um Modelo de Maturidade para Governança Ágil em Tecnologia da Informação e Comunicação isys - Revista Brasileira de Sistemas de Informação, Rio de Janeiro, vol. 8, No. 4, pp. 44-79, 2015 


\begin{tabular}{|l|l|}
\hline & $\begin{array}{l}\text { Revisão Sistemática da Literatura; } \\
\text { Survey com Especialistas; } \\
\text { Grupo Focal. }\end{array}$ \\
\hline À Natureza das Variáveis & $\begin{array}{l}\text { Quantitativa; } \\
\text { Qualitativa. }\end{array}$ \\
\hline Ao Método de Abordagem & Indutiva. \\
\hline Aos Métodos de Procedimento & $\begin{array}{l}\text { Comparativo; } \\
\text { Estruturalista. }\end{array}$ \\
\hline
\end{tabular}

Este trabalho foi idealizado por meio de um conjunto de atividades estruturadas em duas fases distintas. A Figura 1 apresenta ambas as fases.

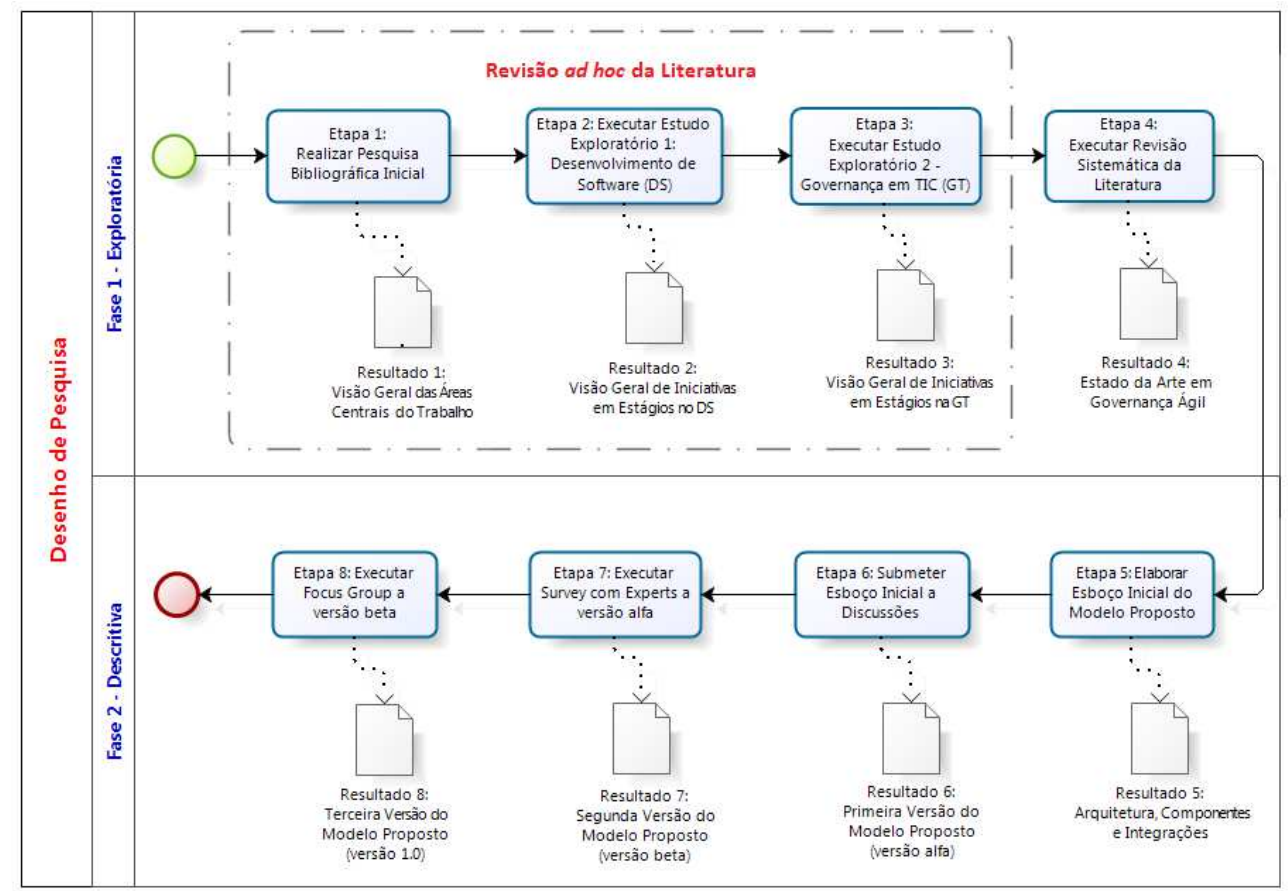

Figura 1 - Processo de Pesquisa para construção do modelo proposto

A primeira fase é composta por um conjunto de quatro etapas. Sua característica é mais exploratória e tem o objetivo de construção de um arcabouço teórico consistente para suporte as etapas posteriores da pesquisa.

Em um primeiro momento, buscando obter uma visão geral a respeito dos objetos de investigação, foi realizada uma pesquisa bibliográfica inicial abordando os temas centrais da pesquisa. Esta etapa gerou um referencial teórico consistente envolvendo principalmente: Governança em TIC; agilidade no desenvolvimento de software; modelos de maturidade e capacidade. Em seguida, foram executados dois estudos exploratórios. O primeiro estudo buscou identificar iniciativas para evolução de maturidade no desenvolvimento de software. O segundo buscou identificar iniciativas para evolução de maturidade na Governança em TIC (ALMEIDA NETO et al., 2012a, 2012b, 2012c, 2012d, 2012e).

Além disto, visando reforçar o arcabouço teórico inicialmente constituído, foi realizado um levantamento do estado da arte da Governança Ágil. Este levantamento seguiu um rigoroso processo metodológico a partir de uma revisão sistemática de literatura. Inicialmente esta revisão sistemática tratou de estudos até 2011 (inclusive). 
Em seguida, esta mesma revisão passou por uma atualização para incluir estudos até 2013 (inclusive) (LUNA et al., 2014).

Os resultados obtidos na primeira fase da pesquisa serviram de alicerce para o desenvolvimento das etapas posteriores. A segunda fase apresenta uma característica mais descritiva com vistas à construção e melhoria contínua do modelo proposto.

Em uma primeira etapa foi então idealizado um esboço inicial do modelo sendo este composto por uma arquitetura, pela definição dos seus respectivos componentes e integrações com outras iniciativas em Governança Ágil. Em seguida, este esboço inicial foi submetido a discussões internas ao grupo de pesquisa e entre membros das comunidades científicas e da indústria. Como fruto destes feedbacks, o modelo foi então evoluído para uma versão alfa (ALMEIDA NETO; MOURA; CAMPOS DE MAGALHAES, 2014; ALMEIDA NETO; MOURA, 2014; NETO et al., 2014).

$\mathrm{Na}$ etapa seguinte, foi executado um survey com especialistas, onde esta versão alfa pode ser avaliada por um universo mais amplo de profissionais. As informações coletadas a partir deste estudo serviram de base para geração de uma versão beta do modelo proposto (ALMEIDA NETO et al., 2015a). Em uma etapa seguinte, foi então executada uma avaliação por meio de grupo focal (ALMEIDA NETO et al., 2015b). Baseado nos resultados obtidos neste estudo foi então gerada uma nova versão (versão 1.0) do modelo de maturidade proposto. A Seção a seguir apresenta o modelo proposto (em sua versão 1.0) seguido de suas respectivas avaliações para as versões alfa e beta.

\section{Modelo Proposto}

O modelo proposto foi denominado de MAnGve Maturity Model (M3) sendo estruturado por meio de três componentes básicos: Um Método de Avaliação (MA), um Modelo de Referência (MR) e uma Base de Experiências (BE). O principal objetivo do MR é a descrição dos processos especificados para o modelo. O MA, por sua vez, é um método que orienta a execução de avaliações de conformidade segundo o MR. Por fim, a BE é tida como um repositório onde são registradas as experiências das avaliações executadas. Este trabalho apresenta foco no MR.

Além disto, o M3 foi construído para permitir a integração com outras iniciativas para Governança Ágil desenvolvidas no âmbito do mesmo grupo de pesquisa $^{2}$ (LUNA, 2009; LUNA; KRUCHTEN; MOURA, 2013; PEDROSA, 2014).

\subsection{Metamodelo e Ciclo de Vida}

Um modelo conceitual é normalmente utilizado no projeto de sistemas de informação e pretende de uma maneira abstrata demonstrar relacionamentos entre os seus componentes (HEUSER, 1998). No escopo deste trabalho, foi criado um modelo conceitual sob forma de um metamodelo para o MR. Este metamodelo define os elementos básicos que estruturam o MR e o relacionamento entre estes (Figura 2).

\footnotetext{
${ }^{2}$ http://gp2.cin.ufpe.br/

ALMEIDA NETO, H. R.; MAgAlHÃES, E. M. C.; MOURA, H. P.; et al.

Avaliação de um Modelo de Maturidade para Governança Ágil em Tecnologia da Informação e Comunicação iSys - Revista Brasileira de Sistemas de Informação, Rio de Janeiro, vol. 8, No. 4, pp. 44-79, 2015
} 


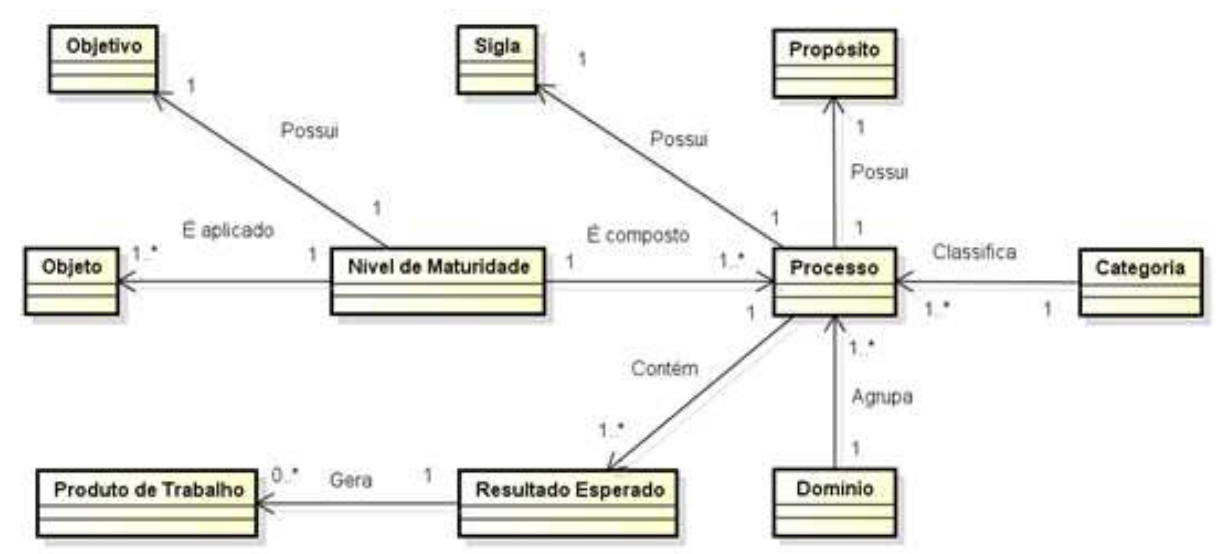

Figura 2 - Elementos Básicos do Modelo de Referência (MR)

Segundo este metamodelo é possível observar que:

- Cada Nível de Maturidade possui um único objetivo, é composto de um ou mais processos e pode ser aplicado a um ou mais objetos.

O Objetivo descreve o propósito do nível de maturidade e está relacionado a um único nível de maturidade.

- O Objeto descreve o contexto ao qual pode ser aplicado o nível de maturidade, e deve ser atribuído, no mínimo, um nível de maturidade ao objeto. Estes objetos podem ser, por exemplo, a organização como um todo ou mesmo parte dela (um setor, uma diretoria, uma unidade de negócio, entre outras).

- O Processo deve conter um conjunto de resultados esperados e um propósito único. Um processo apresenta uma descrição de atuação a partir de um nome de maneira simples e objetiva. Desta forma, um processo pode ser visto como um conjunto de ações correlacionadas que são executadas com vistas a gerar resultados esperados. Um processo também possui uma sigla única e só pode ser classificado em uma única categoria e agrupado em um único domínio.

- O Propósito está associado a um único processo e direciona a organização para a evolução por meio da descrição de objetivos que norteiam a realização dos processos.

- A Sigla define um acrônimo único para o processo.

- Os Resultados Esperados definem os resultados a serem obtidos após a execução do processo e podem gerar um conjunto de produtos de trabalho.

- Os Produtos de Trabalho podem ou não ser gerados a partir de um Resultado Esperado.

- A Categoria classifica um conjunto de processos em processos de Governança em TIC e processos de Gestão Estratégica em TIC.

- O Domínio agrupa um conjunto de processos segundo seus objetivos específicos. Estes domínios são: Garantir, Gerenciar e Monitorar.

Além disto, foi também estabelecido um ciclo de vida para utilização do modelo proposto baseado em quatro etapas conforme PDCA - Plan, Do, Control e Act (PALADINI, 2004). 
- Etapa 1 - Planejamento: Seu principal objetivo é o planejamento das etapas para utilização do modelo;

- Etapa 2 - Apresentação: Seu principal objetivo é a apresentação da estrutura e componentes do modelo proposto, junto aos requisitos necessários para o avanço de maturidade em Governança Ágil em TIC.

- Etapa 3 - Diagnóstico: Seu principal objetivo é executar um diagnóstico de maturidade, expondo forças, fraquezas e oportunidades de melhoria para a organização.

- Etapa 4 - Aperfeiçoamento: Seu principal objetivo é promover o alcance de níveis mais avançados de maturidade, baseado nos resultados da etapa anterior.

É importante deixar claro que este ciclo de vida não possui intenção de substituir o componente MA do modelo de maturidade proposto.

\subsection{Níveis de Maturidade e Processos}

Os processos especificados para o modelo proposto foram construídos com base na norma ISO/IEC 15504 (ISO/IEC 15504-1, 2004). Para tal, cada processo foi descrito em termos de um único propósito e de um conjunto de resultados esperados. As organizações geram os resultados esperados, conforme executam os processos, e estes resultados podem servir como indicadores de desempenho.

O modelo de maturidade proposto neste trabalho busca representar seu conhecimento em Governança Ágil em TIC por meio de níveis de maturidade. Estes níveis foram estruturados com base no conhecimento adquirido durante todo o processo de pesquisa. Como resultado, o M3 foi concebido mediante cinco níveis. Estes níveis variam de 1 (Inicial) ao nível 5 (Em Otimização). São estes:

\section{- Nível 1 - Inicial}

Neste nível as organizações podem apresentar evidências para uma boa Governança Ágil em TIC, mas de maneira ad-hoc. Isto quer dizer que neste nível as organizações não são caracterizadas essencialmente pela ausência total de iniciativas para Governança Ágil em TIC, mas que estas, quando existentes, são realizadas de maneira não sistemática e aleatória, dificultando assim seu avanço em maturidade.

\section{- Nível 2 - Parcialmente Gerenciado}

Neste nível a organização começa a estruturar suas capacidades básicas para uma boa Governança Ágil em TIC, as quais deverão começar a ser preparadas para lidar com os desafios emergentes.

\section{- Nível 3 - Gerenciado}

Neste nível, as capacidades básicas para uma boa Governança Ágil em TIC conseguem ser estruturadas e novas capacidades iniciam sua institucionalização.

\section{- Nível 4 - Estratégico}

Neste nível, os processos para uma boa Governança Ágil em TIC são consolidados. A estratégia para a TIC passa a ser melhor gerenciada, promovendo transparência e melhor definição de uma Arquitetura Empresarial para a organização. 


\section{- Nível 5 - Em Otimização}

Este último nível possui foco em melhoria contínua. Promover otimizações nas iniciativas já implantadas e um maior incentivo à inovação, são tidos como seus pontos chave. A prospecção, seleção e avaliação de novas tecnologias e paradigmas para apoio a uma Governança Ágil em TIC ainda mais efetiva recebe especial atenção neste nível de maturidade.

Quanto aos seus processos, o MR foi especificado a partir de influências dos meta princípios para Governança Ágil em TIC:

- Boa o Suficiente: O nível de Governança deve ser sempre adaptado ao contexto organizacional.

- Orientada aos negócios: O negócio deve ser a razão para cada decisão e ação.

- Focada no Humano: As pessoas precisam se sentir valorizadas e incentivadas a participar criativamente.

- Baseado em Quick Wins (conquistas rápidas): As Quick Wins (conquistas rápidas) têm de ser celebradas e usadas para gerar mais impulso e obter mais resultados.

- Abordagem sistemática e adaptativa: As equipes devem desenvolver a capacidade intrínseca de lidar sistematicamente com mudanças.

- Design simples e refinamento contínuo: As equipes devem entregar rápido e melhorar sempre.

Estes meta princípios foram identificados a partir de uma revisão sistemática de literatura considerando estudos até 2013 (LUNA et al., 2014). Tais meta princípios guiaram a construção do modelo proposto. A Figura 3 apresenta os níveis e siglas dos processos do modelo proposto.

O modelo também recebeu influências da ISO/IEC 15504 (ISO/IEC 15504-1, 2004); da ISO/IEC 38500 (ISO/IEC 38500, 2008); do MAnGve (LUNA, 2009); do CMMI (SEI, 2010a); do MPS.BR (SOFTEX, 2012); do COBIT 5 (ISACA, 2012). 


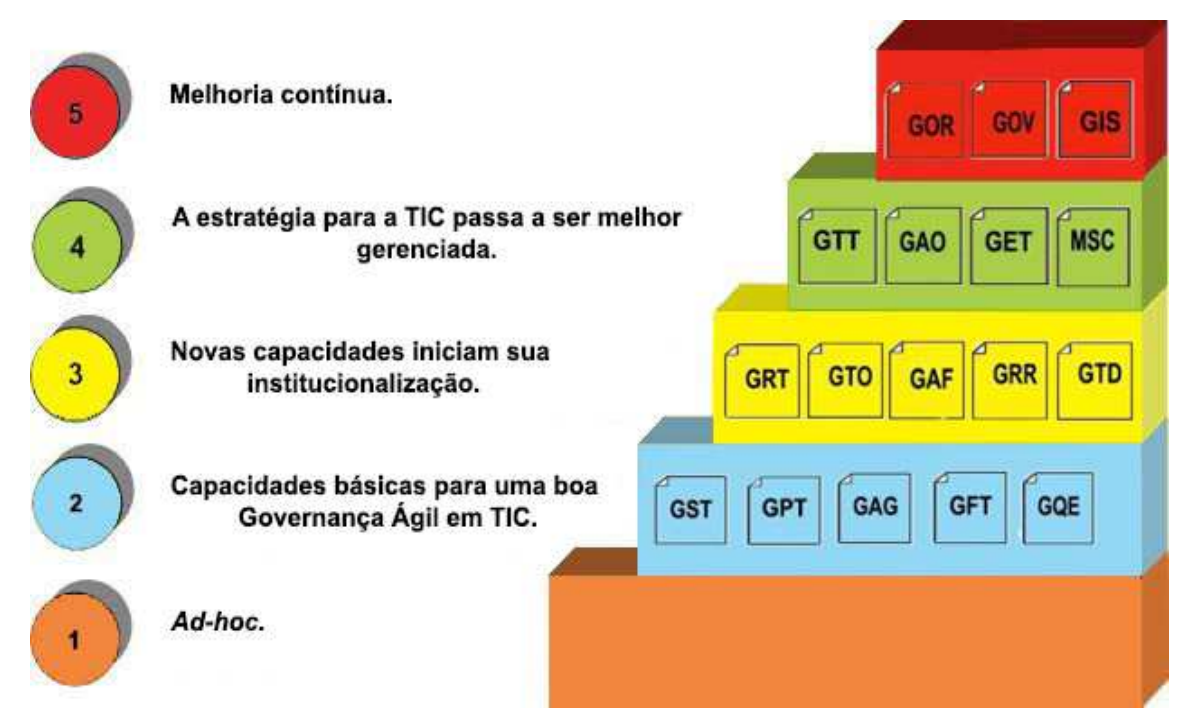

Figura 3 - Níveis de Maturidade e Siglas dos Processos do Modelo Proposto

O Quadro 2 apresenta os processos e níveis construídos para o M3, bem como as influências recebidas por cada um destes segundo os meta princípios para Governança Ágil. É importante observar que todos os processos seguem a ontologia: Garantir, Gerenciar ou Monitorar conforme COBIT 5 (ISACA, 2012). 
Quadro 2 - Níveis, Processos e Influências para Governança Ágil.

\begin{tabular}{|c|c|c|}
\hline Níveis & Processos do Modelo Proposto (versão 1.0) & $\begin{array}{l}\text { Influências recebidas dos Meta Princípios para } \\
\text { Governança Ágil }\end{array}$ \\
\hline \multirow{3}{*}{5} & Garantir Otimização de Recursos (GOR) & Orientada ao Negócio + Focada no Humano \\
\hline & Garantir Otimização de Valor para TIC (GOV) & $\begin{array}{l}\text { Orientado ao Negócio + Boa o Suficiente + } \\
\text { Conquistas Rápidas }\end{array}$ \\
\hline & Gerenciar Inovação em Soluções (GIS) & Design Simples e Refinamento Contínuo \\
\hline \multirow{4}{*}{4} & Garantir Transparência da TIC (GTT) & Design Simples e Refinamento Contínuo \\
\hline & Gerenciar Arquitetura Organizacional (GAO) & Design Simples e Refinamento Contínuo \\
\hline & Gerenciar Estratégia para a TIC (GET) & Recebe Influência dos 6 meta princípios. \\
\hline & Monitorar Sistemas de Controle (MSC) & Orientado ao Negócio + Boa o Suficiente \\
\hline \multirow{5}{*}{3} & Gerenciar Relacionamentos com a TIC (GRT) & Orientada ao Negócio + Focada no Humano \\
\hline & Gerenciar Time Organizacional (GTO) & Focada no Humano \\
\hline & Gerenciar Atividades Financeiras (GAF) & Abordagem Sistemática e Adaptativa \\
\hline & Gerenciar Riscos Relacionados (GRR) & $\begin{array}{l}\text { Abordagem Sistemática e Adaptativa + Design } \\
\text { Simples e Refinamento Contínuo }\end{array}$ \\
\hline & Garantir Tomadas de Decisão para a TIC (GTD) & Orientado ao Negócio + Boa o Suficiente \\
\hline \multirow{5}{*}{2} & Gerenciar Serviços de TIC (GST) & $\begin{array}{l}\text { Abordagem Sistemática e Adaptativa + Design } \\
\text { Simples e Refinamento Contínuo }\end{array}$ \\
\hline & Gerenciar Portfólio da TIC (GPT) & Conquistas Rápidas \\
\hline & Gerenciar Agilidade na Gestão da TIC (GAG) & Orientada ao Negócio + Focada no Humano \\
\hline & Gerenciar Fornecedores da TIC (GFT) & Focada no Humano \\
\hline & Gerenciar Qualidade das Entregas (GQE) & $\begin{array}{l}\text { Abordagem Sistemática e Adaptativa + Design } \\
\text { Simples e Refinamento Contínuo }\end{array}$ \\
\hline 1 & Ad-hoc & Não possui processos \\
\hline
\end{tabular}

\section{Avaliações do Modelo Proposto}

Esta Seção apresenta as avaliações realizadas com o modelo de maturidade proposto. Conforme já apresentado anteriormente no Desenho da Pesquisa (Figura 1), o MAnGve Maturity Model (M3) foi avaliado por meio de um survey com especialistas e um grupo focal. Estes estudos foram de fundamental importância para a avaliação e consequente evolução do modelo proposto por este trabalho de pesquisa. As seções a seguir apresentam os resultados obtidos, bem como o processo seguido em cada um dos estudos realizados.

\subsection{Survey com Especialistas}

De acordo com TEIXEIRA FILHO (2010), alguns paradigmas vêm sendo amplamente utilizados para definição de objetivos e escopo de avaliações de modelos, metodologias e processos, tais como QFD (Quality Function Deployment), GQM (Goal Question Metric) e SQM (Software Quality Metrics). Dentre estes, o método GQM se apresenta como um dos mais indicados para o planejamento, definição dos objetivos de medição e avaliação (BASILI; CALDIERA; ROMBACH, 1994; TRAVASSOS; GUROV; AMARAL, 2002).

No contexto deste trabalho, o GQM foi utilizado com o objetivo de realizar uma das etapas de avaliação do modelo de maturidade proposto (conforme Figura 1). Esta 
estratégia se baseou no trabalho de TEIXEIRA FILHO (2010). Para tal, tornou-se necessário o estabelecimento de alguns objetivos visando à concepção de questões que orientaram a definição de suas métricas (BASILI; CALDIERA; ROMBACH, 1994).

O objetivo principal desta avaliação foi demonstrar o grau de importância, capacidade confiabilidade e coerência dos processos (seus propósitos e resultados esperados) definidos para o modelo proposto. Para tal, foi realizada uma pesquisa envolvendo 61 participantes detentores de conhecimento nas áreas de: Governança em TIC; agilidade no desenvolvimento de software; e/ou modelos de maturidade e capacidade. Estes participantes expressaram suas opiniões por meio de um questionário online, o qual foi anteriormente submetido a um pré-teste junto a três especialistas em Governança Ágil em TIC (MARCONI; LAKATOS, 2008).

Durante o planejamento e definição deste estudo, foram definidos os principais elementos do GQM. Nesta avaliação foram observados aspectos como: importância dos resultados esperados de cada processo, capacidade das organizações em atingir estes resultados esperados, confiabilidade destes e coerência segundo o contexto de Governança Ágil em TIC. O Quadro 3 apresenta a definição do GQM para avaliação do modelo proposto.

O critério "importância" tem por objetivo qualificar melhor o processo e seus resultados esperados do ponto de vista de sua necessidade e valor agregado. $\mathrm{O}$ critério "capacidade", por sua vez, diz respeito à aceitação do processo e seus resultados esperados pela organização e capacidade de conseguir gerar estes resultados esperados. O critério "confiabilidade" foca em levantar o quanto a organização se sentiria segura para aplicar o processo e gerar seus resultados esperados. Por fim, a métrica "coerência" preocupa-se em avaliar o contexto dos processos e seus resultados esperados, ou seja, se estes estão bem especificados e em harmonia com o contexto de Governança Ágil em TIC.

A partir disto, tornou-se então possível a definição de questões visando à avaliação do modelo de maturidade proposto e as métricas necessárias à obtenção das respostas. Sendo assim, foram definidas as seguintes questões para este estudo:

- Questão 1: Busca identificar a importância dos propósitos e resultados esperados. As métricas M1 e M2 foram utilizadas para respondê-la.

- Questão 2: Busca identificar se há capacidade em aplicar os propósitos e obter os resultados esperados propostos para os processos. As métricas M1 e M3 foram utilizadas para respondê-la.

- Questão 3: Busca identificar a confiabilidade dos propósitos e resultados esperados dos processos. As métricas M1 e M4 foram utilizadas para respondêla.

- Questão 4: Busca identificar se os propósitos e resultados esperados dos processos estão coerentes com o contexto de Governança Ágil em TIC. As métricas M1 e M5 foram utilizadas para respondê-la. 
Quadro 3 - GQM para avaliação do modelo proposto

\begin{tabular}{|l|l|l|}
\hline \multirow{2}{*}{ Objetivo } & Propósito (objetivo) & Avaliar a viabilidade do modelo proposto. \\
\cline { 2 - 3 } & $\begin{array}{l}\text { Questão Chave (com } \\
\text { respeito) }\end{array}$ & $\begin{array}{l}\text { Com respeito aos critérios associados a viabilidade da Governança Ágil em } \\
\text { TIC (importância, capacidade, confiabilidade e coerência). }\end{array}$ \\
\cline { 2 - 3 } & $\begin{array}{l}\text { Objeto } \\
\text { (no contexto de) }\end{array}$ & $\begin{array}{l}\text { Do ponto de vista de detentores de conhecimento em: Governança em TIC; } \\
\text { agilidade no desenvolvimento de software; e/ou modelos de maturidade e } \\
\text { capacidade. }\end{array}$ \\
\hline Questão & Q1 & $\begin{array}{l}\text { Qual o nível de importância dos propósitos e dos resultados esperados dos } \\
\text { processos para as organizações? }\end{array}$ \\
\hline Quétrica & M1 & $\begin{array}{l}\text { Escala de } \text { Likert }(1 \text { a 5); } \\
\text { Cálculo do nível de importância: NIP = (TR*TIP)/100; }\end{array}$ \\
\hline Métrica & Q1 & $\begin{array}{l}\text { As organizações tem capacidade de aplicar os propósitos e obter os } \\
\text { resultados esperados dos processos? }\end{array}$ \\
\hline Questão & Q3 & $\begin{array}{l}\text { Escala de Likert (1 a 5); } \\
\text { Cálculo do nível de capacidade: NCP = (TR*TCP)/100; }\end{array}$ \\
\hline Métrica & $\begin{array}{l}\text { M1 } \\
\text { M4 }\end{array}$ & $\begin{array}{l}\text { Os propósitos e os resultados esperados dos processos são confiáveis para } \\
\text { as organizações? }\end{array}$ \\
\hline Questão & Q4 & $\begin{array}{l}\text { Escala de Likert (1 a 5); } \\
\text { Cálculo do nível de confiabilidade: NCF = (TR*TCF)/100; }\end{array}$ \\
\hline Métrica & $\begin{array}{l}\text { M1 } \\
\text { M5 }\end{array}$ & $\begin{array}{l}\text { Os propósitos e os resultados esperados dos processos estão coerentes ao } \\
\text { contexto de Governança Ágil em TIC? }\end{array}$ \\
\hline
\end{tabular}

Para responder estas questões, cinco métricas foram definidas. A métrica M1 é aplicada às quatro questões, e as demais apresentam foco específico a cada questão em particular. Para coleta de dados, foi definida uma escala de pontuação baseada na escala de Likert (MARCONI e LAKATOS, 2009). Segundo GIL (2009), ao responder a um questionário baseado neste tipo de escala, é possível verificar o nível de concordância com uma determinada afirmação.

Sendo assim, para este estudo, foi utilizada a escala Likert variando de 1 a 5 , onde o estágio 1 representou a menor nível e o estágio 5 o maior nível. Além disto, foram ainda definidas as seguintes métricas:

- Métrica M1: Baseada na Escala de Likert, onde cada nível (variando entre 1 e 5) é tido como uma opção de resposta. Para que fossem alcançadas as respostas às questões, os participantes indicaram um único valor (variando entre 1 e 5) para cada resultado esperado de cada processo elaborado para o modelo em questão.

- Métrica M2: Tido como o Cálculo do Nível de Importância (NIP), busca responder, dentro de uma regra de três, o nível de importância dos propósitos e resultados esperados dos processos, de acordo com os resultados obtidos com a métrica M1. Para tal, o total de respostas (TR) foi multiplicado pelo total de respostas por nível (TIP) e dividido por 100.

- Métrica M3: Tido como o Cálculo do Nível de Capacidade (NCP), busca responder, dentro de uma regra de três, o nível de capacidade em aplicar os propósitos e resultados esperados dos processos, de acordo com os resultados 
obtidos com a métrica M1. Para tal, o total de respostas (TR) foi multiplicado pelo total de respostas por nível (TCP) e dividido por 100.

- Métrica M4: Tido como o Cálculo do Nível de Confiabilidade (NCF), busca responder, dentro de uma regra de três, o nível de confiabilidade dos propósitos e resultados esperados dos processos, de acordo com os resultados obtidos com a métrica M1. Para tal, o total de respostas (TR) foi multiplicado pelo total de respostas por nível (TCF) e dividido por 100.

- Métrica M5: Tido como o Cálculo do Nível de Coerência (NCE), busca responder, dentro de uma regra de três, o nível de coerência dos propósitos e resultados esperados dos processos, segundo o contexto de Governança Ágil em TIC e de acordo com os resultados obtidos com a métrica M1. Para tal, o total de respostas (TR) foi multiplicado pelo total de respostas por nível (TCE) e dividido por 100 .

Conforme descrito, a população ou universo para este estudo foi composta por participantes com experiência em: Governança em TIC; agilidade no desenvolvimento de software; e/ou evolução de maturidade. Com relação à esta experiência, foi observado que $73,8 \%$ dos respondentes participaram ou têm participado direta ou indiretamente de iniciativas para apoio a Governança em TIC, 42,6\% participaram ou têm participado direta ou indiretamente de iniciativas para apoio a evolução de maturidade e 78,7\% participaram ou têm participado direta ou indiretamente de iniciativas envolvendo práticas e/ou valores ágeis. A Figura 4 apresenta a forma de atuação e os anos de experiência dos participantes deste estudo.

Além disto, também foi observado que mais da metade dos respondentes $(73,4 \%)$ possuíam juntos "entre 1 e 5 anos" e "entre 5 e 10 anos" de experiência com foco em Governança em TIC, mais da metade dos respondentes $(84,6 \%)$ possuíam juntos "entre 1 e 5 anos" e "entre 5 e 10 anos" de experiência com foco em evolução de maturidade e mais da metade dos respondentes $(89,6 \%)$ possuíam juntos "entre 1 e 5 anos" e "entre 5 e 10 anos" de experiência com foco em práticas e/ou valores ágeis. 


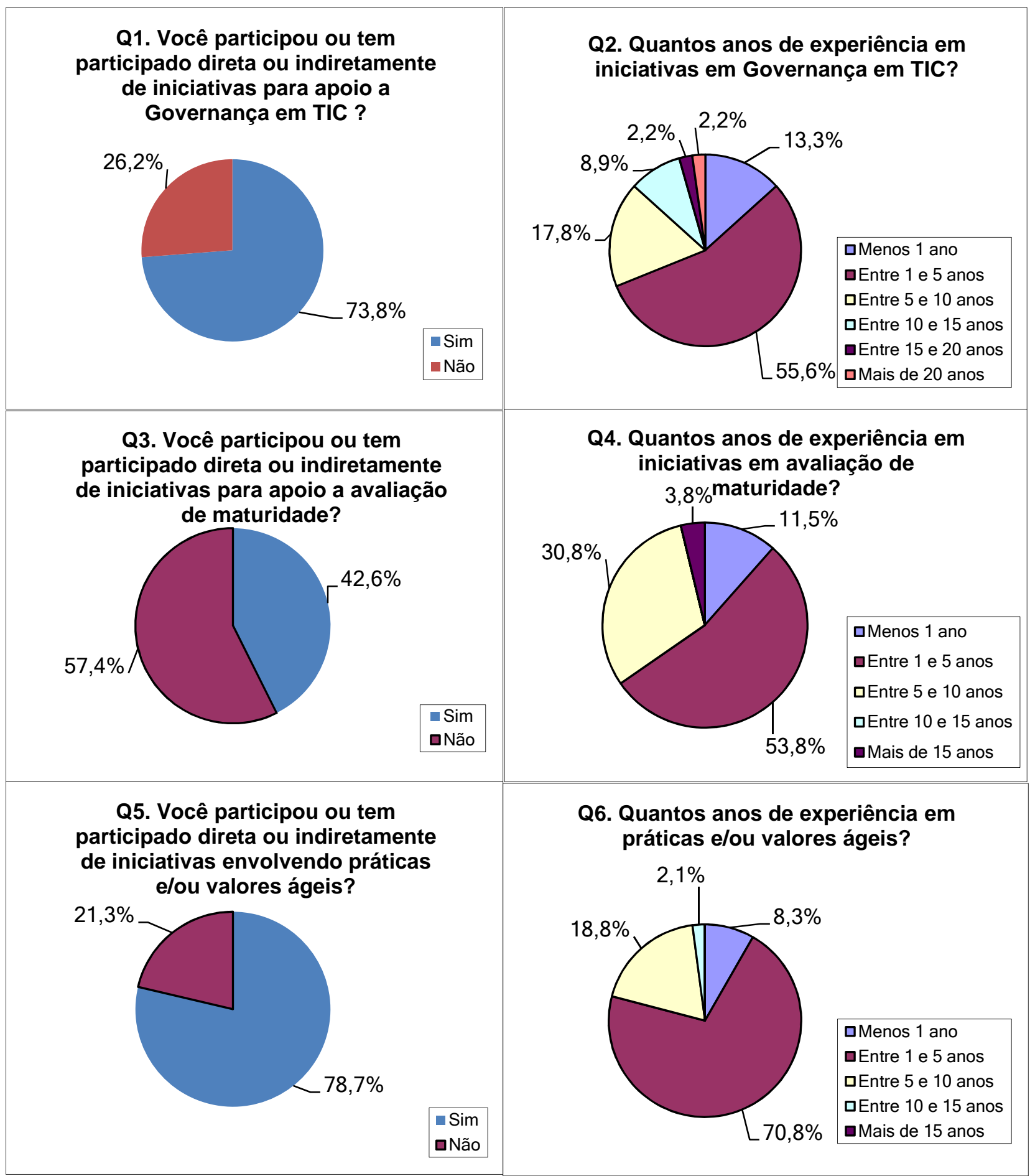

Figura 4 - Atuação e Experiência dos Participantes 
Entre os cargos/funções preferencialmente sugeridos para a pesquisa podemos destacar: Presidentes (CEO - Chief Executive Officer) ou Diretores Executivos; Diretores de Informática (CIO - Chief Information Officer); Gerentes de TI/Coordenadores de TI; Gerentes de Projetos/Coordenadores de Projetos; Consultores; Professores; Pesquisadores; entre outros. A Figura 5 apresenta a distribuição percentual dos cargos e funções dos participantes deste estudo.

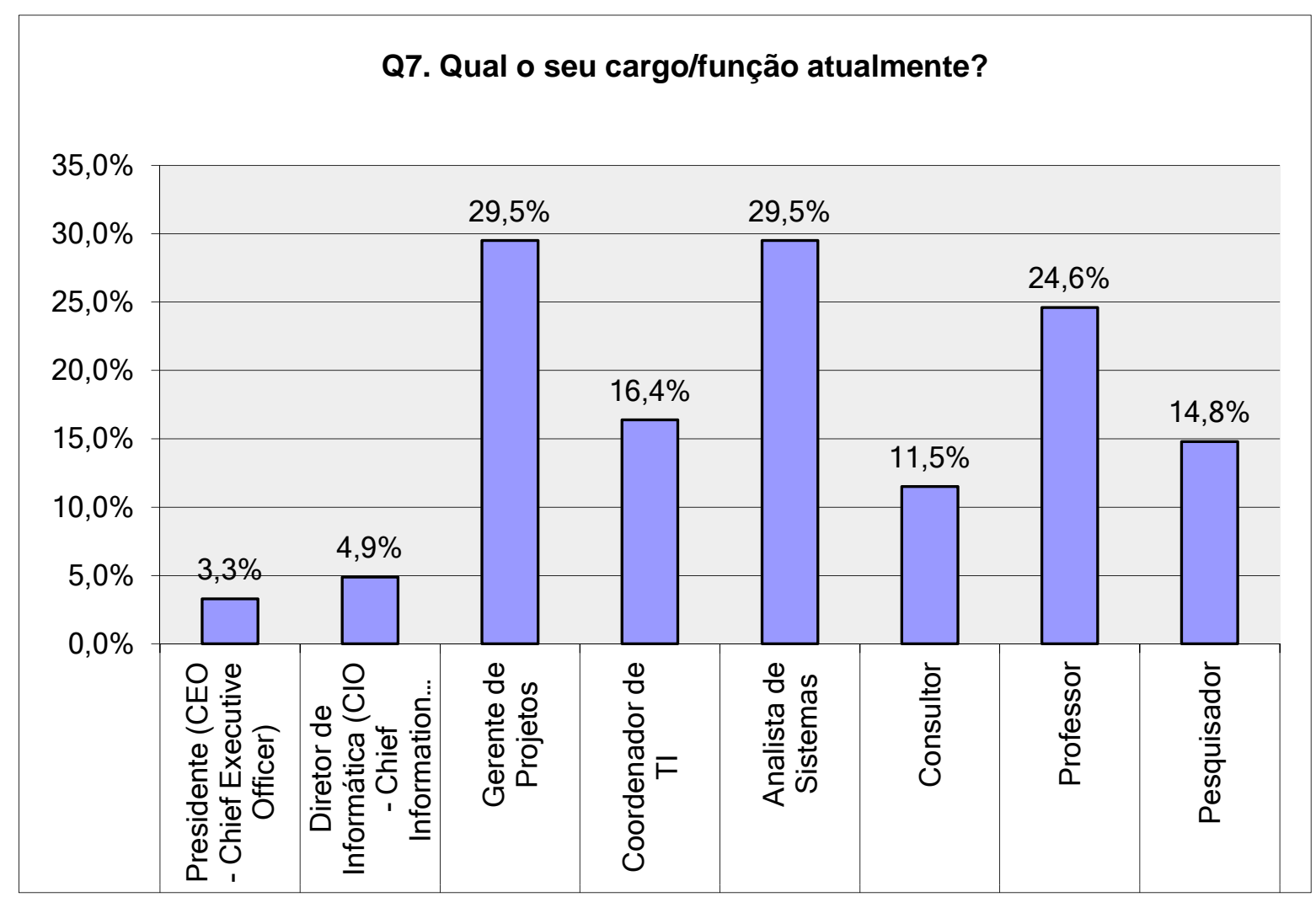

Figura 5 - Cargos/Funções dos participantes do estudo

GIL (2009) aponta quatros fatores que podem determinar o tamanho da amostra:

- A amplitude do universo;

- O nível de confiança;

- O erro máximo permitido;

- A percentagem com que o fenômeno se verifica, considerada muito importante para a determinação do tamanho da amostra.

A amplitude do universo pode ser classificada como finita (não excede a 100.000 elementos) ou infinita (excede a 100.000 elementos). O nível de confiança se refere à área da curva "normal" definida a partir dos desvios-padrão em relação à sua média, onde um desvio-padrão corresponde a aproximadamente 68,0\% de nível de confiança, dois desvios correspondem a aproximadamente $95,5 \%$ de nível de confiança e três desvios correspondem a aproximadamente $99,7 \%$ de nível de confiança. O erro máximo permitido, por sua vez, é expresso em termos percentuais e, normalmente, varia entre $3,0 \%$ e $5,0 \%$ em pesquisas sociais. Por fim, a percentagem com que o fenômeno se verifica é considerada muito importante para a determinação do tamanho da amostra. 
O último relatório do IBGE (IBGE - INSTITUTO BRASILEIRO DE GEOGRAFIA E ESTATÍSTICA, 2009) sobre o setor de Tecnologia da Informação e Comunicação - TIC brasileiro foi utilizado como base para definição do tamanho da amostra. Neste relatório consta que, no ano de 2006, o país possuía 65.754 empresas que empregavam 673.024 pessoas na área de TIC. Desta forma, considerando que o número de empresas e profissionais de TIC tiveram um aumento nos últimos anos, foi adotada a seguinte fórmula para o cálculo de amostras para populações infinitas (excede a 100.000 elementos) considerada na teoria da amostragem (GIL, 2009):

$$
n=\frac{\sigma^{2} \cdot \rho \cdot q}{e^{2}}
$$

Onde: $\mathrm{n}=$ tamanho da amostra;

$\sigma^{2}=$ nível de confiança escolhido, expresso em número de desvios-padrão;

$p=$ percentual com o qual o fenômeno se verifica;

$q=$ percentual complementar $(100-p)$;

$\mathrm{e}^{2}=$ erro máximo permitido.

Para este estudo utilizou-se a amostragem probabilística do tipo estratificada proporcional (GIL, 2009; MARCONI; LAKATOS, 2008). O estudo considerou a população da pesquisa superior a 100.000 possíveis participantes de TIC. Ficou estabelecido que o número de participantes de TIC se situaria por volta de 3,0\%, portanto $q$ é igual a $100-3$, ou seja, 97 .

Em seguida, adotou-se um nível de confiança de 95,5\% (corresponde a dois desvios-padrão) e um erro máximo de 5,0\%. Aplicando-se a fórmula encontrou-se o seguinte resultado:

$$
n=\frac{2^{2} \cdot 3 \cdot 97}{5^{2}}=\frac{1164}{25}=46,56
$$

Logo, para atender às exigências estabelecidas pelo estudo, o número de elementos da amostra deveria contar com a resposta de no mínimo 46,56 participantes.

No decorrer do estudo, os participantes puderam informar um número baseado na escala de Likert (entre 1 e 5), registrando assim suas opiniões para cada um dos processos do modelo proposto (envolvendo seus propósitos e resultados esperados). Além disto, os participantes também puderam relatar críticas e/ou sugestões para cada um dos processos avaliados. Por fim, os participantes foram questionados quanto a disposição dos processos perante os níveis propostos para o MAnGve Maturity Model (M3) e puderam relatar opiniões gerais a respeito do modelo proposto.

Durante a fase de coleta de dados, um questionário foi utilizado como instrumento. Este questionário foi elaborado por meio da ferramenta online SurveyMonkey ${ }^{3}$. O questionário foi distribuído por meio de disponibilização de seu link de acesso via email e em grupos específicos (linkedin, facebook, googlegroups). O

${ }^{3}$ http://www.surveymokey.com

ALMEIdA NETO, H. R.; MAgALHÃES, E. M. C.; MOURA, H. P.; et al.

Avaliação de um Modelo de Maturidade para Governança Ágil em Tecnologia da Informação e Comunicação isys - Revista Brasileira de Sistemas de Informação, Rio de Janeiro, vol. 8, No. 4, pp. 44-79, 2015 
questionário apresentou os propósitos e resultados esperados de cada um dos processos do modelo proposto, além da definição dos critérios que deveriam ser utilizados durante as avaliações (importância, capacidade, confiabilidade e coerência). O questionário online esteve disponível no período de 30/06/2014 à 30/09/2014.

No decorrer deste estudo, foi assegurado o sigilo dos dados e da identificação pessoal a cada um dos participantes. Foram também considerados como critérios de exclusão, os sujeitos que não se enquadraram no perfil da pesquisa, aqueles que não aceitaram participar voluntariamente e aqueles que não responderam completamente ao questionário.

Um total de 93 questionários foram respondidos, no entanto, apenas 61 destes foram considerados válidos e 32 foram descartados por não atender aos critérios previamente estabelecidos. O principal critério para descarte foi o preenchimento parcial do questionário. Desta forma, a amostra total para este estudo acabou sendo composta por 61 respondentes. Esta amostra foi considerada estatisticamente significativa, uma vez que eram necessários no mínimo 46,56 participantes segundo a teoria de probabilidade anteriormente descrita.

Durante a análise dos dados, foi observado que grande parte dos respondentes possuía especialização $(31,1 \%)$ e mestrado $(42,6 \%)$ e desempenhavam suas atividades principalmente como Gerentes de Projetos (29,5\%) ou Analistas (29,5\%). Foi observada também uma considerável participação de professores e pesquisadores, $(39,4 \%)$ para o estudo.

Com relação a experiência e atuação nas áreas centrais da pesquisa foi observado que $73,8 \%$ dos respondentes participaram ou tem participado direta ou indiretamente de iniciativas para apoio a Governança em TIC, 42,6\% participaram ou tem participado direta ou indiretamente de iniciativas para apoio a evolução de maturidade e $78,7 \%$ participaram ou tem participado direta ou indiretamente de iniciativas envolvendo práticas e/ou valores ágeis.

Além disto, também foi observado que mais da metade dos respondentes $(73,4 \%)$ possuíam juntos "entre 1 e 5 anos" e "entre 5 e 10 anos" de experiência com foco em Governança em TIC, mais da metade dos respondentes $(84,6 \%)$ possuíam juntos "entre 1 e 5 anos" e "entre 5 e 10 anos" de experiência com foco em evolução de maturidade e mais da metade dos respondentes $(89,6 \%)$ possuíam juntos "entre 1 e 5 anos" e "entre 5 e 10 anos" de experiência com foco em práticas e/ou valores ágeis.

A opinião dos profissionais de mercado envolvidos na pesquisa contribuiu bastante para evolução desta versão do modelo proposto. Além disto, as visões acadêmicas e científicas apresentadas por Professores e Pesquisadores durante o estudo, agregaram bastante neste sentido. A seguir são apresentadas as análises das respostas coletadas por este estudo. 


\subsubsection{Análise das respostas: Índice Global do M3 (versão alfa)}

A partir da opinião dos 61 participantes, os propósitos e resultados esperados de todos os processos do modelo foram analisados. Desta forma, foi possível obter uma percepção geral do modelo proposto partindo das respostas a cada questão definida a partir do GQM.

As métricas M1 e M2 serviram de base para responder a questão Q1, obtendo-se assim os seguintes percentuais representando o "índice global de importância": totalmente importante $(34,96 \%)$, muito importante $(30,83 \%)$, importante $(23,83 \%)$, pouco importante $(6,65 \%)$ e sem importância $(3,72 \%)$.

Já as métricas M1 e M3 serviram de base para responder a questão Q2, obtendose a partir destas os seguintes percentuais representantes do "índice global de capacidade": totalmente capaz (16,39\%), muito capaz $(28,81 \%)$, capaz $(32,19 \%)$, pouco capaz $(16,11 \%)$ e sem capacidade $(6,49 \%)$.

Por outro lado, as métricas M1 e M4 foram a base para resposta a questão Q3, obtendo-se a partir destas os seguintes percentuais representantes do "índice global de confiabilidade": totalmente confiável $(15,76 \%)$, muito confiável $(27,81 \%)$, confiável $(34,30 \%)$, pouco confiável $(15,42 \%)$ e sem confiabilidade $(6,72 \%)$.

Por fim, as métricas M1 e M5 apoiaram a construção da resposta à questão Q4, obtendo-se a partir destas os seguintes percentuais representantes do "índice global de coerência": totalmente coerente $(21,03 \%)$, muito coerente $(25,69 \%)$, coerente $(32,94 \%)$, pouco coerente $(13,49 \%)$ e sem coerência $(6,84 \%)$. A Figura 6 apresenta estes resultados.

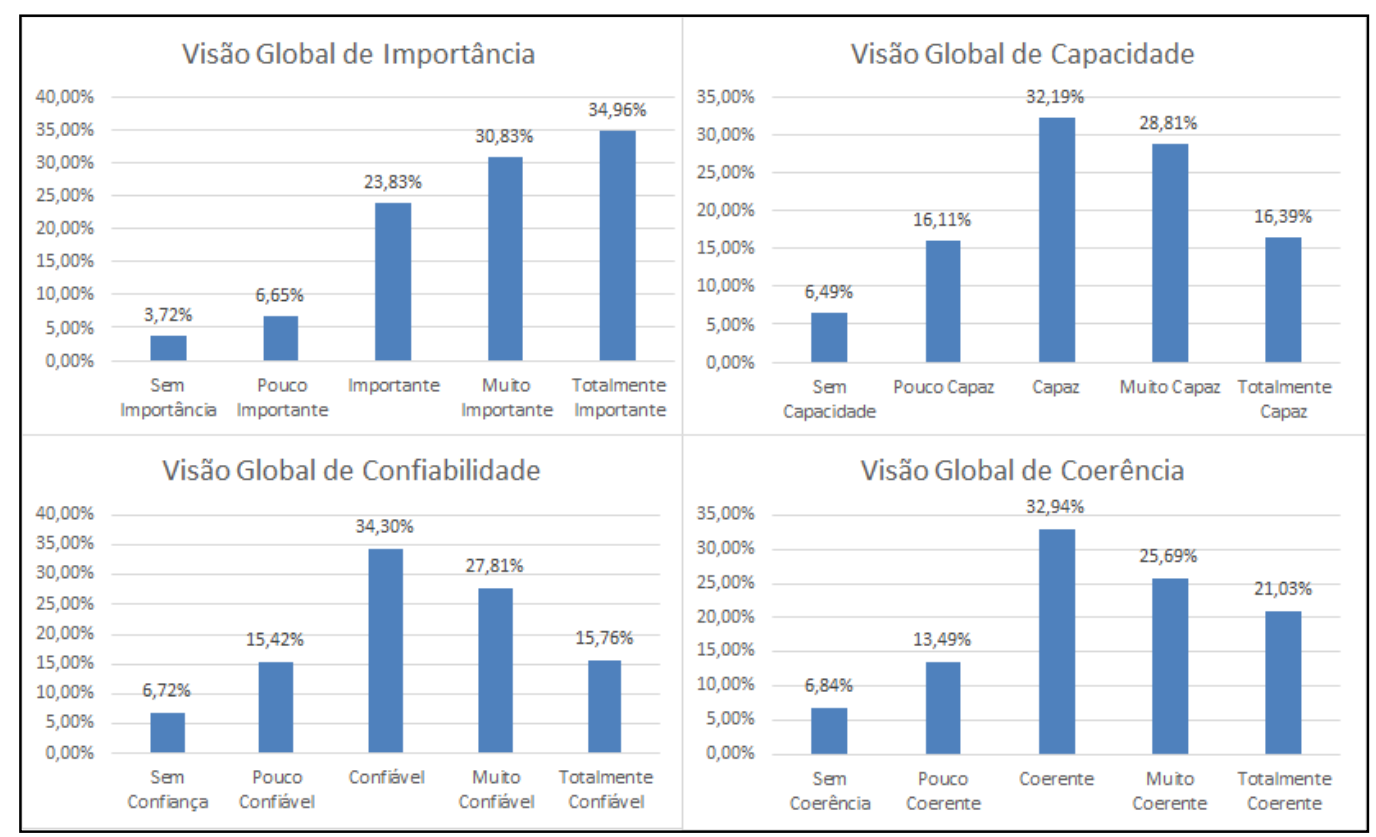

Figura 6 - Índices Globais do Modelo Proposto

Desta forma, torna-se possível afirmar, baseado nos maiores percentuais de respostas obtidas, que em termos importância o modelo foi considerado "muito importante" ou "totalmente importante" por $65,79 \%$ dos participantes. Por outro lado, 
com relação a capacidade, o modelo foi considerado "capaz" ou "muito capaz" por $61,00 \%$ dos participantes.

Analisando estes dados, foi observado que, na opinião dos participantes, o modelo apresenta relevante nível de importância para Governança Ágil em TIC. Além disto, estes participantes apresentam a partir de suas avaliações uma considerável capacidade de utilização do modelo proposto, segundo seus processos (propósitos e resultados esperados), sem expressivas dificuldades.

No que diz respeito a confiabilidade, o modelo foi considerado como "confiável" ou "muito confiável" por $62,11 \%$ dos participantes. Já com relação a coerência, o modelo foi considerado "coerente" ou "muito coerente" por 58,64\% dos participantes.

Podemos então concluir que na visão dos participantes, o modelo apresenta consideráveis níveis de confiabilidade e coerência. Isto indica que os objetivos principais poderão ser alcançados por meio de processos bastante confiáveis e que estes processos estão escritos de forma clara e de fácil compreensão.

\subsubsection{Análise das respostas: Índices dos Processos do M3 (versão alfa)}

Além de uma análise com uma visão mais global a respeito do modelo proposto, foi também realizada uma análise com vistas a demonstrar quais processos obtiveram os melhores desempenhos segundo os quatro critérios estabelecidos para este estudo. Por exemplo, o processo "Preparar os Acordos de Nível de Serviços (PAS)" apresentou o maior índice para os critérios de "Totalmente Importante", "Totalmente Capaz", "Totalmente Confiável" e "Totalmente Coerente" respectivamente com 57,38\%, $24,59 \%, 29,51 \%$ e $32,79 \%$ das opiniões. Este processo é composto por um propósito e dois resultados esperados.

Para os participantes da pesquisa, este processo apresentou como maiores concentrações percentuais em cada critério: totalmente importante $(57,38 \%)$, totalmente capaz $(24,59 \%)$, totalmente confiável $(29,51 \%)$ e totalmente coerente $(32,79 \%)$. Diante dos resultados apresentados, pode-se constatar que, na média, 63,93\% dos respondentes consideraram este processo como sendo "muito" ou "totalmente" importante, capaz, confiável e coerente para todos os critérios. A Figura 7 apresenta os índices globais de desempenho do Processo PAS. 


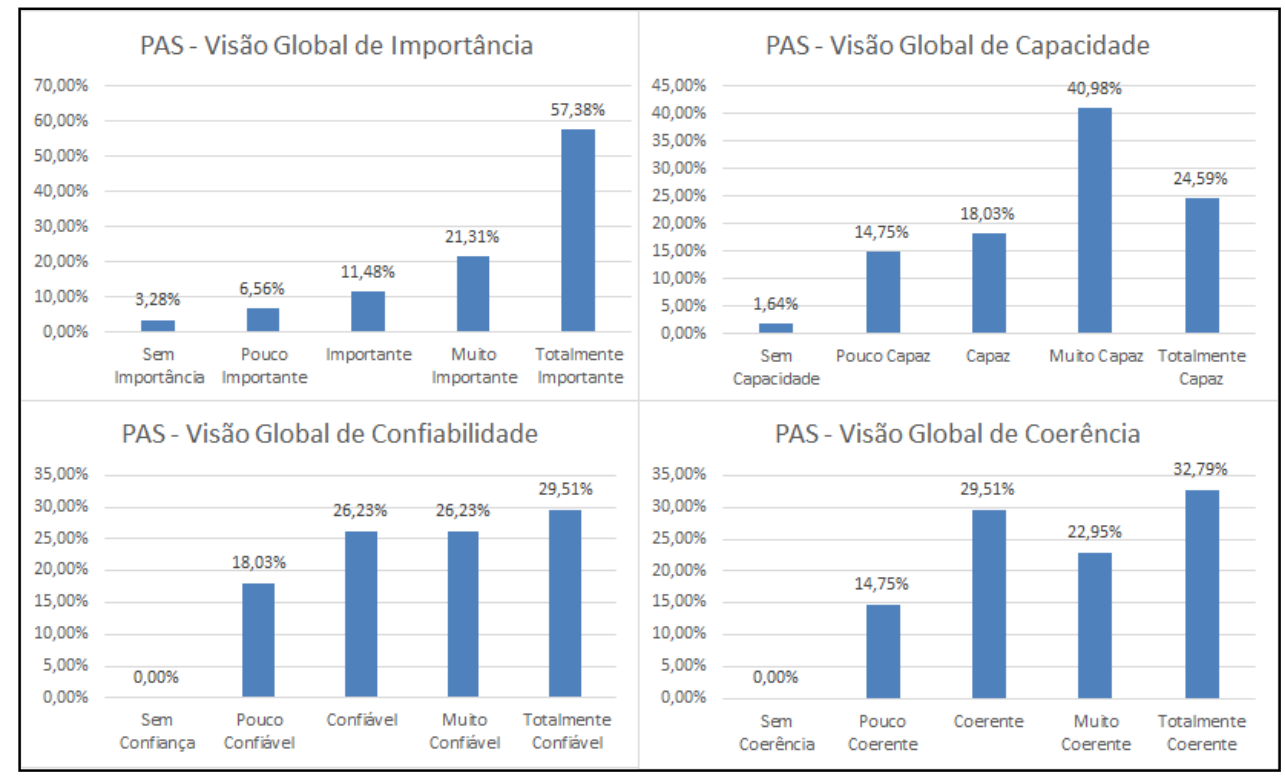

Figura 7 - PAS - Índices do Processo PAS

\subsubsection{Análise das respostas: $M 3$ (versão alfa) em geral}

Além destes questionamentos, os participantes também foram questionados se os níveis do MAnGve Maturity Model (M3) representavam um caminho sistemático e natural para uma Governança Ágil em TIC. Apenas $9,84 \%$ dos participantes responderam que os níveis definidos para o modelo proposto não possuíam esta representatividade. Desta forma, podemos considerar que, na visão de boa parte dos participantes deste estudo, o modelo de maturidade proposto apresenta um caminho sistemático e natural para Governança Ágil em TIC.

Por fim, os participantes foram questionados quanto a comentários gerais para o modelo proposto. Entre estes podemos destacar:

- Comentário 1: “[...] Apesar de tentar conciliar duas visões que geralmente são antagônicas a ideia parece ser bem bacana e adequada a necessidade atual das organizações![...]”.

- Comentário 2: "[...] Acho que seria válido uma revisão em alguns dos propósitos dos processos do modelo e em seus respectivos resultados esperados buscando torná-los mais compreensíveis. [...]”.

- Comentário 3: “[...] Avaliar se o processo DAS do nível 2 pode ser realocado para o nível 3 bem como o processo AAO do nível 3 ser realocado para o nível 2 e o processo GPO ser realocado do nível 2 para o nível 3 [...]".

- Comentário 4: “[...] Verificar se é prudente integrar a preparação da cadeia cliente fornecedor com a definição de acordos de nível de serviço[...]“.

Todos os comentários acima foram devidamente analisados tendo boa parte das sugestões acatadas. 


\subsection{Grupo Focal}

O objetivo principal de um grupo focal é identificar o sentimento de participantes sobre um determinado assunto, produto ou atividade. Os seus objetivos específicos variam de acordo com a abordagem de pesquisa adotada. Em uma pesquisa exploratória, o seu propósito é a geração de novas ideias ou hipóteses, estimulando o pensamento do pesquisador.

Este trabalho realizou uma sessão de grupo focal com o objetivo de avaliar a versão beta do modelo de maturidade proposto. Este estudo se baseou no trabalho de FARIAS JUNIOR (2014). Esta avaliação foi realizada envolvendo especialistas das áreas de Governança em TIC, agilidade e/ou maturidade. Estes especialistas foram convidados a participar do estudo por meio de solicitações formais via e-mail. Para o convite, foram previamente enviados: um resumo da proposta de trabalho e os prérequisitos para participação na pesquisa. Entre estes pré-requisitos foram definidos que os participantes deveriam possuir:

- Pelo menos 2 (dois) anos de experiência em Governança em TIC ou agilidade;

- Pelo menos 2 (dois) anos de experiência em maturidade;

- Preferencialmente certificações nas áreas chave da pesquisa (agilidade, maturidade e/ou Governança em TIC);

- Preferencialmente experiência com desenvolvimento de pesquisas em áreas correlatas.

Definimos estes critérios buscando principalmente fazer com que tanto aspectos de Governança em TIC, como de agilidade e maturidade estavam sendo avaliados durante todo o estudo. Como resultado de nossos convites, seis (6) convidados puderam efetivamente colaborar com a pesquisa. Para tal, foi assinado um termo de confidencialidade para viabilização do estudo proposto. O Quadro 4 apresenta o perfil dos participantes deste estudo.

Entre os participantes é possível identificar: um (1) Mestre, dois (2) Doutores e três (3) Doutorandos, todos em Ciência da Computação. É importante salientar que dois destes participantes têm atuado com uma média de aproximadamente seis (6) anos em Governança Ágil em TIC. Além disto, temos entre os participantes dois (2) consultores em melhorias de processo/implementadores e avaliadores de modelos de qualidade de referência no mercado, um (1) Gerente de Infraestrutura, um (1) Diretor de Governança em Tecnologia da Informação e dois (2) Gerentes de Projeto. Podemos ainda observar que os participantes do estudo possuem uma experiência média de aproximadamente seis (6) anos em maturidade, seis (6) em agilidade e cinco (5) em Governança em TIC. Estes especialistas foram submetidos a uma avaliação tanto da estrutura quanto dos processos do modelo proposto.

A definição sistemática de coleta de dados foi feita a partir de discussões moderadas pelo investigador proponente do modelo de maturidade para Governança Ágil em TIC. Para tal, inicialmente foi realizada uma breve apresentação do M3, visando tornar o método ainda mais eficiente. Em seguida, formulários foram distribuídos para cada um dos participantes contendo as informações que de fato deveriam ser avaliadas. Estes formulários foram estruturados para conter espaços 
reservados onde poderiam ser registradas observações relevantes para discussões durante o estudo. Além disto, estes formulários também foram utilizados posteriormente para uma análise mais detalhada das informações coletadas durante o estudo.

\section{Quadro 4 - Perfil dos Participantes do Estudo}

\begin{tabular}{|c|c|}
\hline Participantes & Função/Certificações/Formação \\
\hline PA1 & $\begin{array}{l}\text { Consultor em melhorias de processo - Implementador e Avaliador de modelos de } \\
\text { qualidade - Auditor líder ISO } 9000 \text { e ISO } 29110 \text {. Implementador e Avaliador Líder inicial } \\
\text { MPS.BR, apto a participar como equipe em avaliações CMMI. Com 12, } 6 \text { e } 7 \text { anos de } \\
\text { experiência respectivamente em maturidade, Governança em TIC e agilidade. Doutorando } \\
\text { com foco em gestão de projetos. }\end{array}$ \\
\hline PA2 & $\begin{array}{l}\text { Consultor em melhorias de processo - Implementador e Avaliador de modelos de } \\
\text { qualidade - Certificado ISTQB, implantador/avaliador MPT, implementador MPS.BR } \\
\text { Serviços. Certificado Scrum Master (CSM), Certificado Scrum Developer (CSD). Criou } \\
\text { um modelo de maturidade para Desenvolvimento Distribuído de Software em seu } \\
\text { Doutorado. Com 5, } 2 \text { e } 3 \text { anos de experiência respectivamente em maturidade, Governança } \\
\text { em TIC e agilidade. }\end{array}$ \\
\hline PA3 & $\begin{array}{l}\text { Diretor de Governança e Tecnologia da Informação - Criou um modelo de maturidade } \\
\text { para Planejamento Estratégico em seu Doutorado. Com } 10,6 \text { e } 5 \text { anos de experiência } \\
\text { respectivamente em maturidade, Governança em TIC e agilidade. }\end{array}$ \\
\hline PA4 & $\begin{array}{l}\text { Gerente de Infraestrutura de TIC - Certificado Scrum Master (CSM), ITIL e COBIT. } \\
\text { Desenvolve pesquisas em Governança Ágil desde 2008. Com } 3,12 \text { e } 13 \text { anos de } \\
\text { experiência respectivamente em maturidade, Governança em TIC e agilidade. Doutorando } \\
\text { com foco em Governança Ágil. }\end{array}$ \\
\hline PA5 & $\begin{array}{l}\text { Gerente de Projetos - Certificado ITIL e COBIT. Desenvolve pesquisas em Governança } \\
\text { Ágil desde } 2011 \text {. Com 2, } 5 \text { e } 4 \text { anos de experiência respectivamente em maturidade, } \\
\text { Governança em TIC e agilidade. Mestre em gestão de projetos. }\end{array}$ \\
\hline PA6 & $\begin{array}{l}\text { Gerente de Projetos - Certificado Scrum Master (CSM). Desenvolve pesquisas em gestão } \\
\text { de projetos desde } 2011 \text {. Com } 2 \text {, } 1 \text { e } 5 \text { anos de experiência respectivamente em maturidade, } \\
\text { Governança em TIC e agilidade. Doutorando com foco em gestão de projetos. }\end{array}$ \\
\hline
\end{tabular}

Antes mesmo do início das análises e preenchimentos destes formulários, foi então informado aos participantes do grupo focal que estes poderiam sentir-se livres para expor opiniões diversas, mesmo quando divergentes das opiniões dos demais participantes.

Durante este grupo focal foram realizados questionamentos que avaliaram o modelo de maturidade proposto quanto:

- A sua estrutura;

- Seus processos;

- O modelo proposto em geral.

As seções a seguir apresentam de forma mais detalhada os resultados obtidos diante deste estudo.

\subsubsection{Análise das respostas: Estrutura do M3 (versão beta)}

O M3 foi concebido inicialmente sobre uma estrutura bidimensional, onde cada dimensão criada era composta por processos específicos. A primeira dimensão do modelo foi composta por processos que continham uma maior ênfase em Governança em TIC, enquanto que a segunda dimensão continha processos com uma maior ênfase em agilidade.

Alguns dos comentários realizados pelos participantes do estudo foram: 
- PA1 comentou: "é preciso avaliar o custo benefício de estruturar o modelo em duas dimensões. A estratégia bidimensional me parece aplicável para contextos mais simples, no entanto, a tentativa de tratar Governança em TIC e agilidade sob uma estrutura bidimensional pode gerar considerável complexidade”.

- PA2 comentou: "estruturar o modelo em dimensões me parece interessante, porém, no atual contexto aplicado, tais dimensões tem tornado o modelo um tanto quanto complexo desnecessariamente”.

- PA3 comentou: "a complexidade de uma estrutura bidimensional como a proposta na atual versão do modelo pode atrapalhar a compreensão e até dificultar a especificação e sinergia entre seus processos".

- PA4 comentou: “me parece que operacionalizar de forma prática um modelo como este, baseado numa estratégia bidimensional, não é uma tarefa nada trivial. Isto foge do que é praticado por alguns dos modelos mais difundidos atualmente no mercado a exemplo do CMMI e do próprio MPS.BR”.

- PA5 comentou: "além da própria unificação desta estrutura bidimensional, é importante avaliar uma maneira de melhor organizar os processos. O COBIT 5, por exemplo, agrupa-os em processos de Gestão e processos de Governança. $O$ CMMI e o MPS.BR também possuem seus próprios agrupamentos de processos".

- PA6 comentou: "Uma boa estratégia para os níveis do modelo proposto seria seguir o quantitativo de níveis do CMMI ou MPS.BR já que são modelos bastante consolidados no mercado".

A princípio, nenhum dos participantes do estudo esteve totalmente em desacordo com esta estrutura bidimensional, porém, após uma análise mais detalhada da estrutura do modelo proposto, foi então sugerida a fusão das dimensões em uma única estrutura. Sob a ótica dos participantes deste estudo, estas dimensões dificultavam tanto a compreensão quanto a operacionalização do modelo proposto. A evolução do modelo até sua versão 1.0 partiu de uma estrutura bidimensional para uma estrutura unidimensional.

Além disto, foi também sugerido que os processos do modelo fossem agrupados em categorias bem definidas, conforme outros modelos já o fazem (por exemplo, o COBIT 5 (ISACA, 2012) classifica seus processos em processos de Gestão e processos de Governança). Sob a ótica dos participantes do estudo, precede aos processos uma estrutura que suporte um ecossistema que os abrigue e os organize. Isto melhora não só a estrutura do modelo proposto como também oferece uma maior clareza quanto ao foco de atuação de cada um de seus processos. Por fim, ainda no quesito estrutura, os participantes sugeriram que o modelo de maturidade proposto buscasse seguir o quantitativo de níveis dos modelos CMMI (SEI, 2010a) ou MPS.BR (SOFTEX, 2012) já que são modelos bastante consolidados atualmente no mercado.

\subsubsection{Análise das respostas: Processos do M3 (versão beta)}

Com relação aos processos, nenhum dos especialistas discordou da importância geral destes para o contexto de Governança Ágil em TIC. No entanto, algumas melhorias 
envolvendo nomenclaturas, siglas e/ou propósitos, foram sugeridas com objetivo de aprimorar o modelo nos quesitos clareza e objetividade.

Alguns dos comentários realizados pelos participantes do estudo foram:

- PA1 comentou: "a princípio, todos os processos apresentam relevância, porém, alguns destes precisam ser refinados com objetivo de torná-los mais claros e objetivos em suas nomenclaturas, siglas elou propósitos".

- PA2 comentou: "apesar da relevância dos processos para o contexto de Governança Ágil em TIC, alguns destes apresentam uma variedade excessiva de verbos em suas nomenclaturas e descrições de propósitos. São utilizados verbos como: Iniciar, "Analisar", "Identificar", "Executar", entre outros. Seria interessante assumir um padrão".

- PA3 comentou: "acredito que, mesmo com a relevância destes processos, alguns possam ser unificados, eliminados e outros incluídos, o que tornaria o modelo menos redundante, com maior foco no estratégico e com maior cobertura de atividades relacionadas à Governança em TIC”.

- PA4 comentou: "alguns processos tem assumido uma postura muito operacional. A meu ver, a Governança em TIC não deve fugir de sua característica estratégica”.

- PA5 comentou: "é importante existir uma relação direta entre as nomenclaturas/siglas de cada processo e seus respectivos propósitos. Neste sentido alguns processos precisam ser refinados visando evitar entendimento dúbio".

- PA6 comentou: "Há processos que apresentam definições de elementos básicos para Governança em TIC na descrição de seus propósitos. Por exemplo, definições de elementos como: Acordo de Nível de Serviços (ANS), Portfólio de Serviços de Tecnologia da Informação e Comunicação (PSTIC), entre outros. Acredito que estas definições não devam fazer parte da especificação do propósito do processo".

$\mathrm{Na}$ visão dos participantes do estudo, as nomenclaturas, siglas e propósitos destes processos precisam ser autoexplicativos. Por exemplo, para o processo "Preparar Acordos de Nível de Serviço (PAS)" foi sugerido que este apresentasse uma nomenclatura/sigla como "Manter Acordos de Nível de Serviço (MANS)". Além disto, seu propósito foi refinado para: "Manter os Acordos de Nível de Serviço (ANS) do Catálogo de Serviços de Tecnologia da Informação e Comunicação". Outros refinamentos semelhantes envolvendo nomenclaturas, siglas e/ou propósitos dos processos também foram discutidos e consolidados durante o estudo.

Durante uma análise mais detalhada dos processos, percebeu-se também que alguns destes estavam assumindo uma postura muito operacional e menos estratégica (principal característica da Governança). Uma reestruturação destes processos também foi alvo de discussões. Uma das questões levantadas neste sentido foi a inclusão de novos processos estratégicos para Governança em TIC (a exemplo de processos envolvendo atividades estratégicas relacionadas a riscos, transparência, financeiro, entre

ALMEIDA NETO, H. R.; MAgALHÃES, E. M. C.; MOURA, H. P.; et al.

Avaliação de um Modelo de Maturidade para Governança Ágil em Tecnologia da Informação e Comunicação iSys - Revista Brasileira de Sistemas de Informação, Rio de Janeiro, vol. 8, No. 4, pp. 44-79, 2015 
outras) e a eliminação de processos mais operacionais (a exemplo de processos como "Desenvolvimento Ágil de Soluções (DAS)").

Por fim, além destes ajustes, também foram sugeridas algumas fusões entre os processos. Tais fusões tiveram como principal objetivo tornar o modelo mais simples e coeso, evitando assim redundâncias desnecessárias. Por exemplo, os processos "Gerenciar Itens do Ciclo de Implantação (GII)" e "Identificar e Planejar Melhorias (IPM)" tiveram sua unificação sugerida devido a sua semelhança em foco de atuação. Algo semelhante também foi discutido para os processos "Identificar e Priorizar Iniciativas de TIC (IPT)" e "Alinhar Iniciativas de TIC com Modelos de Apoio a Governança em TIC (AIG)".

\subsubsection{Análise das respostas: M3 (versão beta) em geral}

Para os participantes do estudo, o M3 apresenta uma proposta interessante e desafiadora para o atual contexto de Governança em TIC. É preciso conciliar as exigências dos controles (internos e externos) organizacionais, com a necessidade por agilidade imposta por um mercado cada vez mais competitivo. O modelo proposto apresenta uma solução inovadora baseado em meta princípios que buscam conduzir a uma Governança Ágil. Baseado em iniciativas de referência do mercado, o modelo proposto pode ser utilizado como uma alternativa de apoio a Governança Ágil em TIC. No entanto, diante das discussões apresentadas durante o grupo focal, podemos observar que o modelo ainda requer aprimoramentos antes de sua aplicação prática em um ambiente real.

\section{Conclusões e Trabalhos Futuros}

Este artigo apresenta os resultados de duas avaliações realizadas com as versões alfa e beta do MAnGve Maturity Model (M3). Os resultados destas avaliações contribuíram para a evolução do modelo proposto, uma vez que tornou possível a obtenção de feedbacks importantes a partir de profissionais ligados diretamente à área. Durante estas avaliações, tornou-se possível identificar melhorias em alguns pontos do M3. Melhorias referentes à sua estrutura, clareza/organização de seus processos (nomenclaturas, siglas e propósitos), quantitativo de níveis de maturidade, entre outras informações gerais envolvendo o modelo proposto puderam ser sugeridas e avaliadas quanto a sua pertinência.

Por fim, as avaliações executadas apontaram o modelo como promissor, ressaltando que este deveria ser colocado em prática em breve (em ambiente real) para real observação de seus benefícios práticos. Entendemos que um modelo como o proposto neste trabalho de pesquisa, apresenta relevantes contribuições tanto para a indústria quanto para a academia. Para indústria, podemos perceber uma iniciativa que estabelece um caminho sistemático e gradual para a adoção de Governança Ágil em TIC em busca de implantações com menor impacto e mais eficiência para as organizações. Já para a academia, entendemos este trabalho como uma contribuição relevante para o avanço de uma área ainda em ascensão e carente de estudos científicos como os executados neste trabalho.

Como trabalhos futuros para esta pesquisa podemos citar:

- Elaborar um banco de melhores práticas para Governança Ágil em TIC; 
- Elaborar um guia de implementação para facilitar a utilização/adoção do modelo proposto;

- Elaborar uma estratégia para representação contínua do modelo de maturidade proposto;

- Criar uma ferramenta online de auto avaliação para fornecer indicativos do nível de maturidade da organização e para sugerir possíveis melhorias;

- Elaborar um portal para disponibilizar toda a documentação do modelo;

- Estabelecer parcerias para adoção e promoção do modelo;

- Definir um processo de certificação que permita capacitar e credenciar profissionais como avaliadores oficiais do modelo de maturidade;

- Realizar estudos de caso para observar, na prática, o comportamento e desempenho do modelo durante sua aplicação.

No que diz respeito a estudos de caso, o modelo de maturidade proposto atualmente está sendo refinado para aplicação em ambientes reais. Uma das organizações interessadas em aplicar o MAnGve Maturity Model (M3) é a IPLAN Empresa Municipal de Informática da Cidade do Rio de Janeiro, a qual, já se colocou a disposição para aplicação em seu ecossistema, inclusive tendo realizado reuniões em agosto do corrente ano para viabilização destes estudos. Espera-se que esta entre outras organizações se beneficiem do MAnGve Maturity Model (M3), ao mesmo tempo em que, apoiém o refinamento contínuo do modelo proposto. 


\section{Referências}

ALMEIDA NETO, H.R.; MAGALHÃES, E. M. C.; MOURA H. P.; TEIXEIRA FILHO, J. G.A.; CAPPELLI, C.; MARTINS, L. M. F. Evaluating a Maturity Model for Agile Governance in Information and Communication Technology with Survey Based on Expert Opinion. 18 Workshop em Engenharia de Software Experimental (ESELAW 2015). Lima, Perú. Anais. 2015a. Disponível em: <eventos.spc.org.pe/cibse2015/CIBSE2015-Proceedings.pdf>. Acesso em: 10/06/2015.

ALMEIDA NETO, H. R. DE; MOURA, H. P. DE. MAnGve Maturity Model (M3): Proposing a Maturity Model to Support Agile Governance in Information and Communication Technology. X Simpósio Brasileiro de Sistemas de Informação Workshop de Teses e Dissertações (WTDSI). Londrina, PR - Brasil. Anais. 2014. Disponível em: <http://www.lbd.dcc.ufmg.br/colecoes/wtdsi/2014/009.pdf>. Acesso em: $10 / 12 / 2014$

ALMEIDA NETO, H. R. DE; MOURA, H. P. DE; CAMPOS DE MAGALHAES, E. M. MAnGve Maturity Model (M3): Towards a Maturity Model to Support Agile Governance in Information and Communication Technologies (ICT). 9th Iberian Conference on Information Systems and Technologies (CISTI). Thesis Workshop. Barcelona, Espanha. Anais. 2014. Disponível em: < http://connection.ebscohost.com/c/articles/97081517/mangve-maturity-model-m3-towardsmaturity-model-support-agile-governance-information-communication-technologies-ict> . Acesso em: 10/12/2014.

ALMEIDA NETO, H. R. DE; MOURA, H. P. DE; CAMPOS DE MAGALHAES, E. M. MAnGve maturity model (M3): A proposal for a doctoral thesis. 9th Iberian Conference on Information Systems and Technologies (CISTI). Barcelona, Espanha. Anais. 2014. Disponível

em: <http://ieeexplore.ieee.org/lpdocs/epic03/wrapper.htm?arnumber=6876909>. Acesso em: $10 / 12 / 2014$.

ALMEIDA NETO, H.R.; MAGALHÃES, E. M. C.; MOURA H. P.; TEIXEIRA FILHO, J. G.A.; CAPPELLI, C.; MARTINS, L. M. F. Avaliação de um Modelo de Maturidade para Governança Ágil em TIC usando Focus Group. XI Simpósio Brasileiro de Sistemas de Informação (SBSI 2015). Disponível em: <http://www.portal.inf.ufg.br/sbsi2015/>. Goiânia - GO, Brasil. Anais. 2015b. Acesso em: 15/06/2015.

BARTENSCHLAGER, J.; GOEKEN, M. IT strategy Implementation FrameworkBridging Enterprise Architecture and IT Governance. Americas Conference on Information Systems (AMCIS) 2010 PROCEEDINGS. Disponível em: $<$ http://aisel.aisnet.org/amcis2010/400/>. Acesso em: 15/06/2015.

BASILI, V.; CALDIERA, G.; ROMBACH, D. H. The Goal Question Metric Paradigm Encyclopedia of Software Engineering, v. 2. USA: John Wiley \& Sons, 1994.

BECK, K.; BEEDLE, M.; VAN BENNEKUM, A.; COCKBURN, A.; CUNNINGHAM, W.; FOWLER, M.; GRENNING, J.; HIGHSMITH, J.; HUNT, A.; JEFFRIES, R.; KERN, J.; MARICK, B. ; MARTIN, R. C.; MELLOR, S.; SCHWABER, K.; SUTHERLAND, J.; 
\& Thomas, D.; Manifesto for Agile Software Development, 2001. Disponível em: $<$ http://agilemanifesto.org/>. Acesso em: 17/08/2015.

BLOOM, A. The Republic of Plato. 2nd. ed. 1991.

CADBURY, A. The Financial Aspects of Corporate Governance. The Committee on the Financial Aspects of Corporate Governance, UK, p. 90, 1992.

CARMEL, E. The Offshoring Stage Model : an epilogue, 2005. Disponível em: <auapps.american.edu/ carmel/papers/epilogue.pdf>. Acesso em: 10/06/2015.

CRAWFORD, J. K. Project Management Maturity Model (CBP - Center for Business Practices). USA: CRC, 2001.

FILHO PAULA; PÁDUA WILSON. Engenharia de Software: Fundamentos, Métodos e Padrões. $3^{\text {a }}$ edição, LTC, Rio de Janeiro, 2009.

GIL, A. C. Métodos e técnicas de pesquisa social. 6. ed. São Paulo: Atlas, 2009.

GRANT, K. P.; PENNYPACKER, J. S. Project management maturity: An assessment of project management capabilities among and between selected industries. IEEE Transactions on Engineering Management, v. 53, n. 1, p. 59-68, 2006.

GREMBERGEN, W. V.; DEHAES, S. D. Implementing Information Technology Governance: Models, Practices and Cases. New York, USA.: IGI Publishing, 2008.

HESTON, K. M.; PHIFER, W. The multiple quality models paradox: how much "best practice"is just enough? Journal of Software Maintenance and Evolution, n. July 2009, p. 517-531, 2011.

HEUSER, C. A. Projeto de Banco de Dados. 4. ed. Instituto de Informática da UFRGS., 1998. v. 4.

IBGE - INSTITUTO BRASILEIRO DE GEOGRAFIA E ESTATÍSTICA. O Setor de Tecnologia da Informação e Comunicação no Brasil. 2003-2006. Disponível em: <http://www.ibge.gov.br/home/estatistica/economia/stic/publicacao.pdf >. Acesso em: 21/03/ 2015.

IBM RATIONAL. Rational Unified Process: Best Practices for Software Development Teams. White 2011. Daper. Disponível em: < http://www.ibm.com/developerworks/rational/library/content/03July/1000/1251/1251_bestp ractices_TP026B.pdf >. Acesso em: 21/03/2015.

ISACA. The Val IT Framework 2.0. 2009. Disponível em: $<$ http://www.isaca.org/knowledge-center/val-it-it-value-delivery-/pages/valit 1 .aspx $? u t m \_s o u r c e=$ multiple\&utm_medium $=$ multiple \&utm_content $=$ friendly\&utm_camp aign=valit $>$. Acesso em: 23/02/2015. 
ISACA. COBIT 5 : A Business Framework for the Governance and Management of Enterprise IT. 1st ed. Rolling Meadows: ISACA, 2012, p. 94.

ISACA. COBIT Case Studies by Industry, 2013. Disponível em: <http://www.isaca.org/Knowledge-Center/cobit/Pages/COBIT-Case-Studies.aspx>

ISEB. The Information Systems Examination Board web site. 2012. Disponível em: <http://www.iseb.org.uk>. Acesso em: 01/10/2012.

ISO/IEC 15504-1. International Organization for Standardization / International Electrotechnical Comission. Information Technology - Process Assessment - Part 1: concepts and vocabulary, Geneve: ISO, 2004.

ISO/IEC 38500. International Organization for Standardization/International Electrotechnical Comission. Information Tecnhology - Corporate governance of information technology. Geneve: ISO, 2008.

ITIL. ITIL (Information Technology Infrastructure Library). 2009. Disponível em: $<$ http://www.best-management-

practice.com/gempdf/itSMF_An_Introductory_Overview_of_ITIL_V3.pdf>. Acesso em: 02/08/2014.

KTATA, O.; LÉVESQUE, G. Agile development: issues and avenues requiring a substantial enhancement of the business perspective in large projects. C3S2E '09 Proceedings of the 2nd Canadian Conference on Computer Science and Software Engineering. 2009. Disponível em: <http://dl.acm.org/citation.cfm?id=1557636>. Acesso em: 18/09/ 2012.

LUNA, A. J. H. DE O. MAnGve: Um Modelo para Governança Ágil em TIC. Dissertação de Mestrado em Ciência da Computação. Programa de Pós-graduação stricto sensu em Ciência da Computação. Universidade Federal de Pernambuco. 2009.

LUNA, A. J. H. de O.; COSTA, C. P.; MOURA, H. P. \& NOVAES, M. A. Agile Governance in Information and Communication Technologies: Shifting Paradigms. JISTEM Journal of Information Systems and Technology Management, v. 7, n. 2, p. 311334, 2010.2 Disponível em: <http://www.jistem.fea.usp.br/index.php/jistem/article/view/10.4301\%252F $\quad$ S180717752010000200004/208>. Acessado em: 17/08/2015.

LUNA, A. J. H. O.; KRUCHTEN, P.; MOURA, H. . GAME: Governance for Agile management of enterprises a management model for agile governance. Proceedings 2013 IEEE 8th International Conference on Global Software Engineering Workshops, ICGSEW 2013, p. 88-90, 2013.2 Disponível em: $<$ http://ieeexplore.iee. $.0 r g / x p 1 / a r t i c l e D e t a i l s . j s p ? a r n u m b e r=6613457>$. Acesso em: $07 / 10 / 2014$.

MARCONI, M. DE A.; LAKATOS, E. M. Técnicas de pesquisa: planejamento e execução de pesquisas, amostragens e técnicas de pesquisa, elaboração, análise e interpretação de dados. 7 ed. São Paulo: Atlas. 2008. 
MARCONI, M. DE A.; LAKATOS, E. M. Metodologia científica. 5. ed. São Paulo: Atlas, 2009.

MARCONI, M.; LAKATOS, E. Fundamentos de metodologia científica.7. ed. São Paulo: Atlas. 2010.

NAWROCKI, J.; WALTER, B.; WOJCIECHOWSKI, A. Toward maturity model for extreme programming. Proceedings 27th EUROMICRO Conference. 2001: A Net Odyssey. Anais. Disponível em: http://ieeexplore.ieee.org/xpl/login.jsp?tp=\&arnumber=952459\&url=http\%3A\%2F\%2Fieee xplore.ieee.org\%2Fxpls\%2Fabs_all.jsp\%3Farnumber\%3D952459>. Acesso em: $18 / 03 / 2015$.

OGC. ITIL Service Design Book - Process Maturity Framework. Appendix H pg 263, 2007.

PALADINI, Edson Pacheco. Gestão da Qualidade: teoria e prática. São Paulo. Atlas, 2004.

PATEL, C.; RAMACHANDRAN, M. Agile maturity model (AMM): A Software Process Improvement framework for agile software development practices. Int. J. of Software Engineering, IJSE, v. 2, n. I, p. 3-28, 2009.

PEDROSA, M. L. G. DO E. MDIGA: Um Modelo de Perfis de indicadores para Governança Ágil em TIC. Dissertação de Mestrado. Universidade Federal de Pernambuco (UFPE), 2014.

PMI - PROJECT MANAGEMENT INSTITUTE. Organization Project Management Maturity Model (OPM3). Newton Square: PMI, 2003.

PRADO, D. S. Maturidade em Gerenciamento de Projetos. Nova Lima: INDG Tecnologia e Serviços Ltda, 2008.

SEI - SOFTWARE ENGINEERING INSTITUTE. The Capability Maturity Model: guidelines for improving the software process. MA: Addison-Wesley, 1995.

SEI - SOFTWARE ENGINEERING INSTITUTE. CMMI-DEV - Capability Maturity Model Integration for Development, version 1.3. Pittsburgh, PA. Software Engineering Institute, Carnegie Mellon University. USA, 2010a.

SOFTEX. MPS.BR - Melhoria de Processo do Software Brasileiro. Guia de Implementação - Parte 10: Implementação do MR-MPS em organizações do tipo Fábrica de Teste. 2011. Disponível em: <http://www.softex.br/wpcontent/uploads/2013/07/MPS.BR_Guia_de_Implementacao_Part e_10_20111.pdf>. Acesso em: 12/10/2014.

SOFTEX. MPS.BR. 2012. Disponível em: <http://www.softex.br>. Acesso em: $21 / 04 / 2015$ 
SOLER, A. OPM3: a Contribuição PMI para Maturidade em Gestão de Projetos. Revista Mundo PM, p. 46-49. v 1, n. 2. ISSN: 1807-8095, 2005.

TEIXEIRA FILHO, J. G. A. MMPE-SI/TI (Gov) - Modelo de Maturidade para Planejamento Estratégico de SI/TI direcionado às Organizações Governamentais Brasileiras baseado em Melhores Práticas. vol. 1 e 2, 2010. Tese (Doutorado em Ciências da Computação) - Universidade Federal de Pernambuco (UFPE), Recife, 2010.

TRAVASSOS, G.; GUROV, D.; AMARAL, E. Introdução à Engenharia de Software Experimental. Relatório Técnico. ES59002Abril. Programa de Engenharia de Sistemas e Computação COPPEUFRJ, p. 52, 2002.

US DEPARTMENT OF STATE. Office of the Historian - Milestones - 1937-1945 - The Bretton Woods Conference, 1944. Online.

WEIL, P.; ROSS, J. W. IT Governance: How Top Performers Manage IT Decision Rights for Superior Results. International Journal of Eletronic Government Research, v. 1, n. 4, p. 63-67, 2005.

YIN, A. Scrum Maturity Model. Dissertação para obtenção do Grau de Mestre em Engenharia Informática e de Computadores. Universidade Técnica de Lisboa, 2011. 